\title{
Application of weather radar CAPPI data to verify NWP rainfall accumulation data
}

\author{
José Marcio Bassan ${ }^{1}$ - João Eduardo Machado Perea Martins ${ }^{2} \cdot$ Shigetoshi Sugahara $^{1}$. \\ Reinaldo Bomfim da Silveira ${ }^{3}$
}

Received: 11 November 2014/Accepted: 17 July 2015/Published online: 4 August 2015

(c) Springer-Verlag Wien 2015

\begin{abstract}
This study presents a method for using the CAPPI data from a weather radar to verify forecasts of $24 \mathrm{~h}$ accumulated precipitation from a numerical weather prediction (NWP) model, during 2010-2012. The radar used in this study consisted of a $2^{\circ}$ beam width, Doppler and single polarization, S-band radar, located at the Meteorological Research Institute (IPMET) of Sao Paulo State University, Bauru, Sao Paulo, Brazil. A tuned version of the Eta model was used in the verification, though any model could be used with a few minor adaptations. The model, used actively at IPMET, had a horizontal grid spacing of $10 \mathrm{~km}$, and was defined with the lateral boundary conditions from the Global Circulation Model of the Center for Weather Forecasting and Climate Research of the Brazilian Institute for Space Research. A linear correction was applied to the radar data, using selected rain gauges from the state of Sao Paulo's meteorological
\end{abstract}

Responsible Editor: C. Simmer.

Reinaldo Bomfim da Silveira

rsilveira@simepar.br

José Marcio Bassan

bassan@ipmet.unesp.br

João Eduardo Machado Perea Martins

perea@fc.unesp.br

Shigetoshi Sugahara

shige@ipmet.unesp.br

1 IPMET, UNESP, Est. Municipal Jose Sandrin SN, Chacara Bauruense, Bauru, SP 17048699, Brazil

2 Department of Computing Sciences, UNESP, Av. Eng. Luiz Edmundo C. Coube, 14-01, Bauru, SP 17033360, Brazil

3 SIMEPAR, Centro Politecnico da UFPR, Jd das Americas, Curitiba, PR 81531980, Brazil observation network, to create a reference series for both radar and NWP quantitative precipitation estimates. The reference data were used to verify the rainfall rates forecasted with the NWP, in terms of both their spatial distribution and the rainfall quantity at ground level. The results agreed well with the specific ranges of rainfall values, but there were situations where the radar data presented limitations for the verification. Ways in which to improve the methodology presented here are discussed. The current study provides an opportunity to use a high-resolution data set to verify predicted rainfall across a large spatial coverage, particularly in places which lack rain observational data.

\section{Introduction}

The state of Sao Paulo, in Brazil, is located between $20.43^{\circ}$ and $25.28^{\circ}$ south, and $44.32^{\circ}$ and $53.05^{\circ}$ west. It stretches from the coast ( $0 \mathrm{~m}$ above sea level; a.s.l.) up to the Pedra da Mina peak in the Sierra da Mantiqueira, $2798 \mathrm{~m}$ a.s.l. According to Peel et al. (2007), the climate in the state is classified as warm temperate, or maritime temperate in the high elevation areas; inhabitants can expect conditions to be warm and moist in the summer, and cold and dry in the winter. However, Peel et al. (2008) performed a long-term data analysis of the daily precipitation regime in the state of Sao Paulo and showed that there has been a change in both the distribution and intensity of precipitation, with a significant trend for a wetter climate, mainly due to the increase of very heavy precipitation events. Liebmann et al. (2001) found that the state of Sao Paulo can experience heavy precipitation events, during which the daily total can reach more than $80 \mathrm{~mm}$. They also described the 
influence of the South Atlantic Convergence Zone (SACZ); this is a zone of enhanced convection activity, which is most pronounced during summer, and extends from the Amazon Basin southeastward into the Atlantic, passing over Sao Paulo. It causes strong precipitation events, which mainly occur close to the coast.

January and February (summer) are the rainiest months in the state of Sao Paulo, with more than $300 \mathrm{~mm} / \mathrm{month}$ recorded in some places. In contrast, May to July is the driest period. The central part of the state follows a wellbehaved climate pattern, in which most of the yearly precipitation occurs during summer, and winter is characterized as a very dry period. In addition, frontal systems often travel from the south to the southeast of Brazil and pass over the Sao Paulo region. Sometimes these frontal systems are preceded by strong squall lines and complex convective mesoscale systems that cause a large amount of precipitation.

The state of Sao Paulo is responsible for most of Brazil's economic output and has the largest population in the country. Agricultural planning, reservoir hydraulic operations and severe weather hazardous mitigation within the state depend on quantitative precipitation forecasting (QPF), which is therefore essential for economic planning. For QPF, the Institute for Meteorological Research (IPMET), of Sao Paulo State University, in Bauru, uses the numerical weather prediction (NWP) Eta model, described by Mesinger et al. (1988) and Chou et al. (2005). However, to assess the quality of the model outputs, as well as to maximize the usefulness of the information, the model requires an adequate verification system. This is often achieved using weather station data, but such data are not always available. In these cases, weather radar data can prove useful. Thus, the institute also maintains an S-band Doppler weather radar, located in Bauru. This study describes a methodology to use the historic data from the S-band Doppler weather radar to verify the NWP daily rainfall accumulation simulations. Within the study, the radar data are firstly verified and corrected, based on rain gauge data and using statistics. Then the corrected radar data are used to verify the NWP data.

Radar data have been applied to verify estimations of rainfall in many studies around the world. For instance, Gabella et al. (2004) compared the daily rainfall estimated by two NWP models with observational data derived from radar and rain gauges, within the Alps. They compared the data using aerial correspondence checks, for point-to-point, two-dimensional images and volumetric analyses, and by examining portions of the data distribution. Their results showed a good agreement between the radar data and rain gauges, but disagreement between one of the models and observations, because the model failed to capture the underlying physical processes controlling the precipitation.
As the horizontal resolution of models increases, weather radar data have been found useful to validate the verification approaches of NWP rainfall distribution estimates, as described by Ebert and Gallus Jr (2009), through the contiguous rain area (CRA) method. A validation of NWP using weather radar data can be found in Berenguer et al. (2005), who also included a review of the main QPF techniques applied for hydrological purposes. In Brazil, Calvetti and Pereira Filho (2014) used radar and satellite data to produce quantitative hourly rainfall estimates, and verify QPF estimates from NWP ensembles, for a hydrological application of the Iguassu river basin, in the state of Parana.

Weather radar data have been used to calculate radar rainfall rate (RR) estimates for almost 70 years (see Laws and Parsons 1943; Marshall et al. 1947; Marshall and Palmer 1948; Marshall et al. 1955). RR is related to the radar reflectivity factor $(Z)$, hereafter defined as the $Z R$ relationship:

$\left.\mathrm{RR}\left[\mathrm{mm} \times \mathrm{h}^{-1}\right]=10^{\left[\frac{Z(\mathrm{~dB})}{(10 \times b)}-\frac{\log a}{b}\right.}\right]$

where $a$ and $b$ are empirically obtained constants and $Z$ is calculated from Probert-Jones equation (1962).

In the present study, the Eq. (1.1) is used to estimate RR from reflectivity values obtained using with the weather radar in Bauru city. The aim here is to define a rainfall rate field that can be used as reference series to verify the rainfall forecasted using a NWP model. Two ZR relationships, identified from many found in the relevant literature, are evaluated:

$Z=200 \times R^{1.6}$ (from Marshall et al. 1955, suitable for stratiform precipitation); and

$Z=250 \times R^{1.2}$, (from Rosenfeld et al. 1993, suitable for convective precipitation).

Discussion about target scattering amplitudes goes beyond the scope of this study; however, the attenuation of radar energy that occurs when the beam passes through a water precipitation area can limit the quantification of the radar return signal. According to Doviak and Zrnic (1984), the attenuation is insignificant for a radar with a wavelength of $10 \mathrm{~cm}$, as used in the present study.

The analysed data from the S-band radar, used in the present study, correspond to $3.5 \mathrm{~km}$ Pseudo-CAPPI data, as described by Vaisala (2014), and hereafter referred to as CAPPI. The radar covers an area of $480 \times 480 \mathrm{~km}^{2}$ (Fig. 1). The Sierra de Botucatu is about $100 \mathrm{~km}$ southeast from the radar. The $3.5 \mathrm{~km}$ CAPPI was found to be the most suitable, covering elevations that are sufficiently high to avoid ground clutter (see Silveira and Holt 2001, for definition and examples) as well as beam blockages, but below the melting layer, at a range of $120 \mathrm{~km}$. 


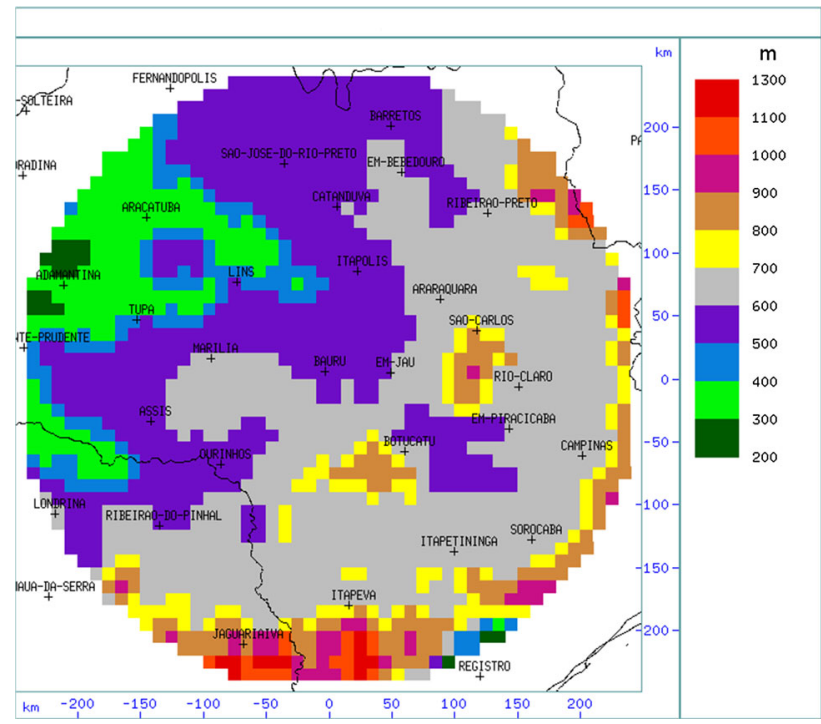

Fig. 1 Map of topography of Sao Paulo state, corresponding to the radar coverage of IPMET's weather radar, reduced to the horizontal grid spacing of $10 \mathrm{~km}$, in accordance to the NWP model grid spacing

Weather radars are susceptible to many problems, such as imprecision resulting from the conversion from the reflectivity factor to ground rainfall rates, the misclassification of hydrometeors and sampling of the volumetric data. This study aims to address these questions and ways to overcome the problems. It also aims to provide a way to derive rainfall accumulation amounts from the weather radar data, to enable the verification of the NWP model rainfall (MR) forecasting outputs. In the next section, the weather radar characteristics and the data used in this study are explained. In Sect. 3, the main characteristics of the atmospheric model are described, as well as the methodology used for its verification with the radar data. The results are presented in Sects. 4, and 5 contains the conclusions and possible applications of the study.

\section{Description of the Bauru weather radar and preparation of the radar data}

The meteorological radar used in this study was located at the IPMET of Sao Paulo State University, in the centre of the state of Sao Paulo, Brazil. It is an EEC S-band (2.8 $\mathrm{GHz}$ ), single polarization and Doppler radar, with beam width of $2^{\circ}$ that is transmitted from a $4 \mathrm{~m}$ diameter antenna, as summarized in Table 1. The radar was controlled through the Radar and Antenna Control system RCP8, and the signal processing software used was the Sigmet RVP8 (Vaisala 2014).

The antenna configuration for this study consisted of continuous volumetric scans of 16 elevations $\left(0.3^{\circ}-45.0^{\circ}\right)$, recording data every $7.5 \mathrm{~min}$, corresponding to 8 datasets per hour. The processor was configured to obtain about 32 samples per ray of every azimuthal scan; this was achieved by allowing pulses of $0.8 \mu$ s to be sent to space at dual frequency scheme of 465 and $620 \mathrm{~Hz}$, a bin spacing of $250 \mathrm{~m}$ and a scan rate of $20 \mathrm{deg} / \mathrm{sec}$. A frequency domain Fast Fourier Transform (FFT), as built in the RVP8 signal processor, was applied to the Doppler power spectrum to filter the ground clutter as well as the second trip echo (Doviak and Zrnic 1984), from digital signal processor (DSP) spectrum.

The rainfall information was only stored through the composition of CAPPI data and corresponds to different heights. As before mentioned, this is a Pseudo-CAPPI, which is a combination of the usual CAPPI data and a filling procedure. Thus, at a given height, a radar parameter was obtained, by interpolation of data from adjacent elevation angles, and the near/far radar ranges were filled with data from highest/lowest elevation angles. To determine the most adequate CAPPI height to be used for rainfall accumulation, an evaluation of the derived rainfall data was performed.

The ground clutter contamination can be visually observed through using the rainfall accumulation data from three CAPPI heights $(2.0,2.75$ and $3.5 \mathrm{~km})$, as depicted in Fig. 2, for 23 March 2010. The amount of ground clutter in neighbourhood of the radar decreases substantially with an increase in height, and no serious effect on the precipitation area was produced. However, clutter echoes remained in the $3.5 \mathrm{~km}$ CAPPI data; most of them were identified by computing the frequency of the accumulated rainfall over the period of $24 \mathrm{~h}$ periods, from 2010 to 2012, for the whole radar domain. Precipitation levels above $0 \mathrm{~mm}$, equal or above $0.1 \mathrm{~mm}$ and equal or above $1.0 \mathrm{~mm}$ were considered (Fig. 3). In addition, large frequency of rainfall events corresponded to radar pixels that were contaminated with clutter (Fig. 3a). To illustrate, one can compare this to the terrain map in Fig. 1; note the position of the mountains surrounding the radar. Applying the $0.1 \mathrm{~mm}$ threshold eliminated most of high frequency echoes, although ground clutter was still observed, as depicted in Fig. 3b. Thus, a further clean up of the ground clutter data was carried out, by eliminating the pixels for which the $24 \mathrm{~h}$ rainfall accumulation was less than $1.0 \mathrm{~mm}$ (Fig. 3c). This was a more conservative threshold, which produces data showing that the rainfall frequency is less than $40 \%$, which agrees with the climatologically observed pattern in the region (not shown, see WMO 1996 for reference of the climatological frequency of rainy days, over $1.0 \mathrm{~mm}$ of accumulation, in the state of Sao Paulo). Although this approach eliminated both ground clutter and precipitation, it guarantees that less contaminated data were used to verify the NWP QPF. 
Table 1 Main Bauru weather radar characteristics

\begin{tabular}{ll}
\hline Characteristics & Values \\
\hline Wavelength & $10.7 \mathrm{~cm}$ \\
Beamwidth & $2^{\circ}$ \\
Pulse length & $2 \mu \mathrm{s}$ \\
Bin resolution & $250 \mathrm{~m}$ \\
Elevations (o) & $0.3,0.8,1.7,2.7$, \\
& $3.6,4.6,5.5,6.4$, \\
& $7.4,9.3,11.1,13.9$, \\
Minimum discernible signal up to $240 \mathrm{~km}$ & $18.3,26.5,34.9$ and 45.0 \\
Radar control processor & $10 \mathrm{dBZ}$ \\
Digital signal processor & $\mathrm{RCP} 8$ \\
Time series processing mode & Vaisala RVP8 \\
Velocity unfolding & FFT \\
High PRF & Dual PRF 4:3 \\
Low PRF & $620 \mathrm{~Hz}$ \\
Maximum range & $465 \mathrm{~Hz}$ \\
Unambiguous range & $240 \mathrm{~km}$ \\
Unambiguous velocity & $241.8 \mathrm{~km}$ \\
Average number of samples per ray & $49.8 \mathrm{~m} / \mathrm{s}$ \\
Clutter filtering & 32 \\
Stored data resolution & Frequency domain based on Doppler spectrum \\
\hline
\end{tabular}

An additional problem of weather radar measurements is the anomalous propagation of electromagnetic waves through the atmosphere, called ANAPROP, described by Bean and Dutton (1968). According to the refractive properties of the atmosphere, the trajectory of the radar beam can bend in excess, which causes multiple reflections towards the ground, at distances that are beyond the maximum radar range. To avoid the use of data with this source of contamination, ANAPROP was manually identified, and the days when the problem occurred were eliminated from the data set. Although this approach was not an automatic procedure, it helped to clean up the radar data prior its use for NWP verification; in total about $7 \%$ of the radar data were eliminated in this way.

One disadvantage of using the $3.5 \mathrm{~km}$ CAPPI data was that, although the height was below the melting layer for the region, there was a large distance $(3.5 \mathrm{~km})$ between the data collection point and the ground. Because of this, atmospheric processes that can affect the precipitation accumulation rates, such as evaporation and advection to neighbouring pixels, might happen in the layer from the surface up to $3.5 \mathrm{~km}$, reducing the accuracy of the data. To overcame part of these effects, further correction of the radar data was applied using the ZR relationship, as discussed below.

Following the data correction for ground clutter and ANAPROP, 3 years of data were selected (2010-2012), to estimate the radar rainfall ( $R R$ ) using the $\mathrm{ZR}$ relationship. To select an adequate $\mathrm{ZR}$, the RR data were compared to three rain gauge precipitation (GP) data sets, from Bebedouro, Jau and Piracicaba, in the state of Sao Paulo (Fig. 4). Whereas the number of rain gauges used in the work will be explained later in this section, these particular gauges were selected because they were in meteorological stations that were well maintained and the data were available under good quality, for the whole period of the work. The RR data were obtained using the RAINN (N-hour rain accumulation) from VAISALA's SIGMET/IRIS (Significant Meteorological Information/Interactive Radar Information System). This derives the rainfall from reflectivity factor values, accumulates them on suitable timeframe and produces the $3.5 \mathrm{~km}$ CAPPI rainfall product. Two estimates of radar rainfall RR were derived using $a$ and $b$ coefficients from Marshall et al. (1955) and Rosenfeld et al. (1993) and compared to the GP.

The overall results show that the radar underestimates the precipitation accumulated over $24 \mathrm{~h}$, when compared to the three rain gauges. Figure 5 depicts the daily accumulation of ground precipitation in Bebedouro, for the period 2010-2012, derived from: Marshall-Palmer ZR relationship at the top, Rosenfeld's ZR in the centre; and the GP at the bottom. There were some peaks in the rainfall derived using Rosenfeld's ZR relationship (i.e. convective precipitation), in which individual values are greater than the GP observations. However, in general rainfalls from both radar 


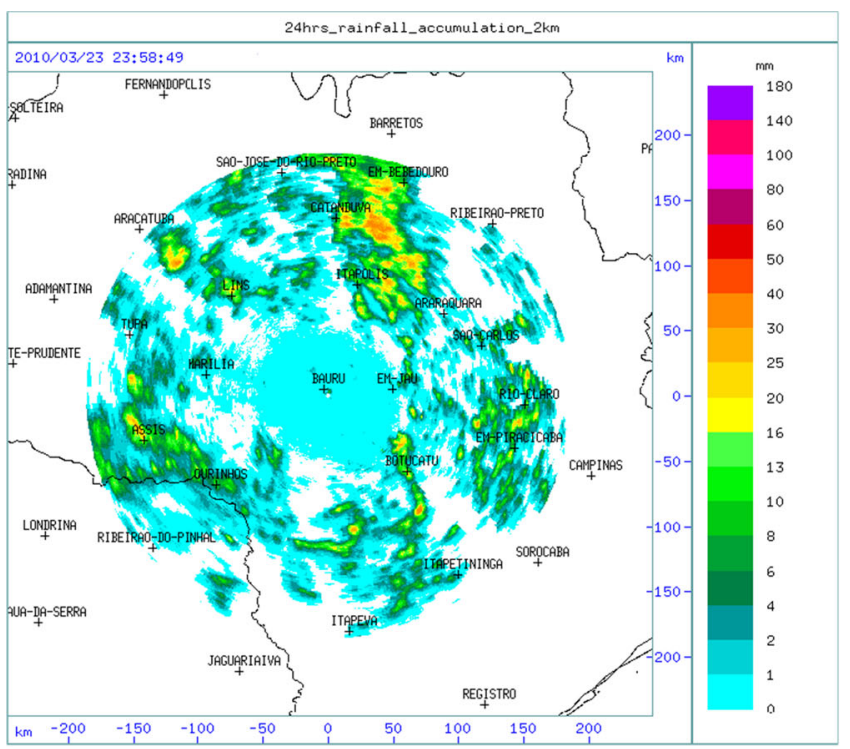

(a)

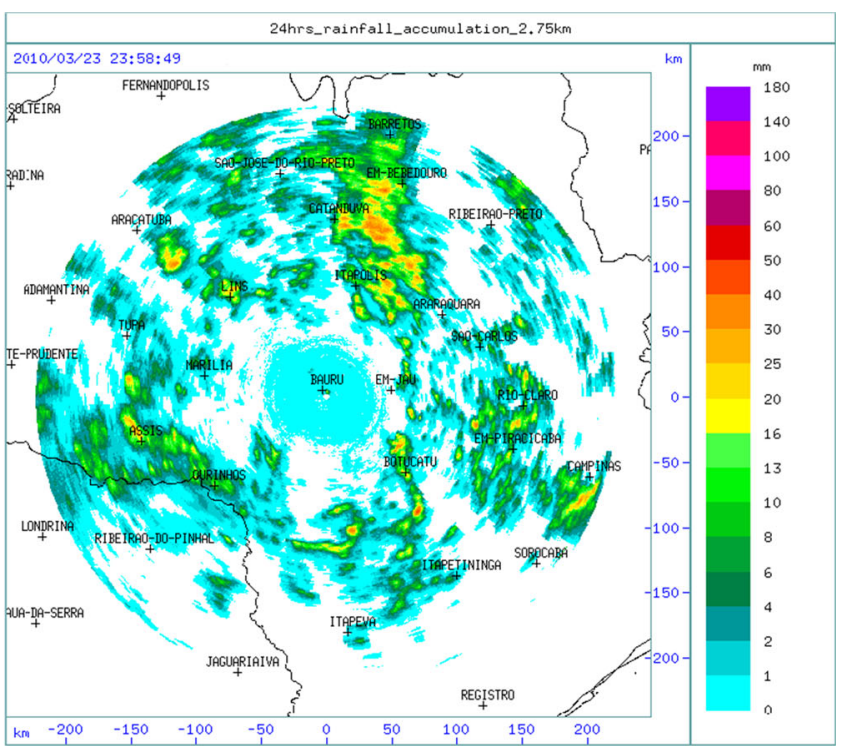

(b)

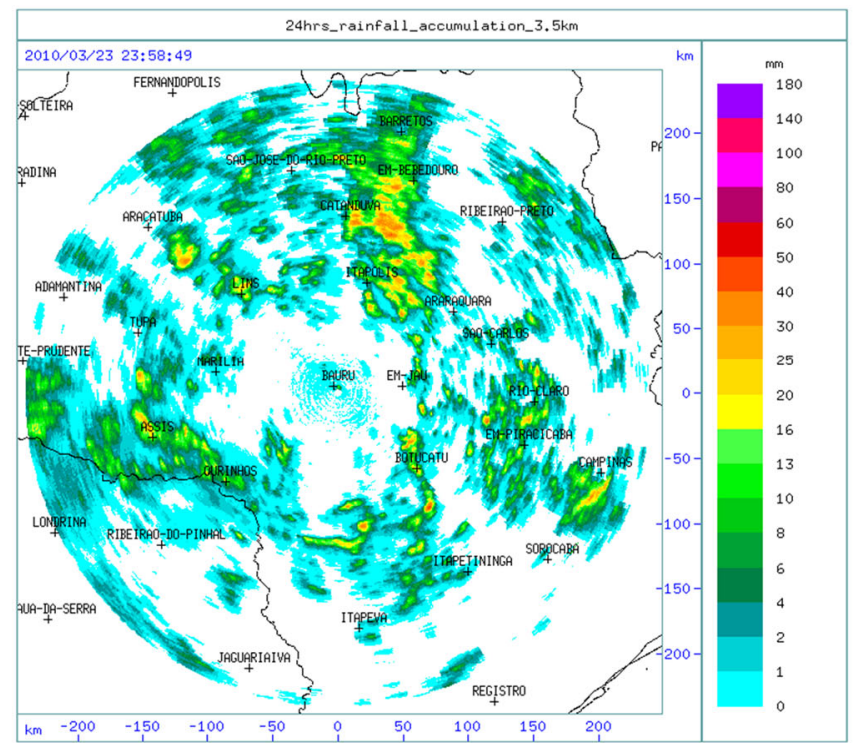

(c)

Fig. 2 Rainfall accumulation over $24 \mathrm{~h}$, derived from IPMET's weather radar and visualized through CAPPI heights, respectively, of a $2.0 \mathrm{~km}$, b $2.75 \mathrm{~km}$ and c $3.5 \mathrm{~km}$, for 23 March 2010

time series underestimate the GP observations, particularly using the Marshall-Palmer relationship. This probably occurs due to the regional rainfall characteristics, which are predominantly convective. The time series for the other two stations are similar (data not shown). In addition, the differences between RR and GP observations (RR-GP) at the three stations, considering both the stratiform and convective ZR relationships, are often negative (Fig. 6).

Statistical comparisons between radar estimated rainfall and that observed with the rain gauges indicate that the radar systematically produced a reasonable estimate of the observed rainfall, despite the differences found and the distances between the stations and the radar (Table 2). Moreover, the scatterplots show a linear correlation between the radar and rain gauge accumulated daily rainfall data, with correlations between 0.69 and 0.81 (Fig. 7). In this figure and in the following derivations, only data that are greater than $1.0 \mathrm{~mm}$ and $(\mathrm{RR}-\mathrm{GP})>(\overline{G P}+2 s d)$ were used, where $s d$ is the GP standard deviation. When the RR data are compared with the aggregated data of the three rain gauges, correlations of 0.76 and 0.71 are found for the RR data derived using the stratiform and convective 


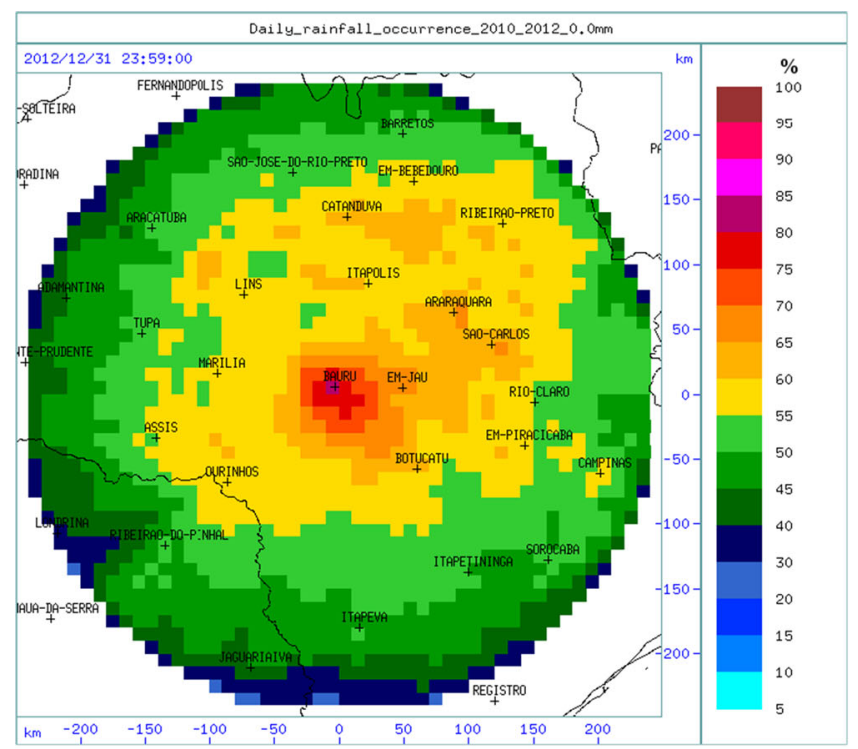

(a)

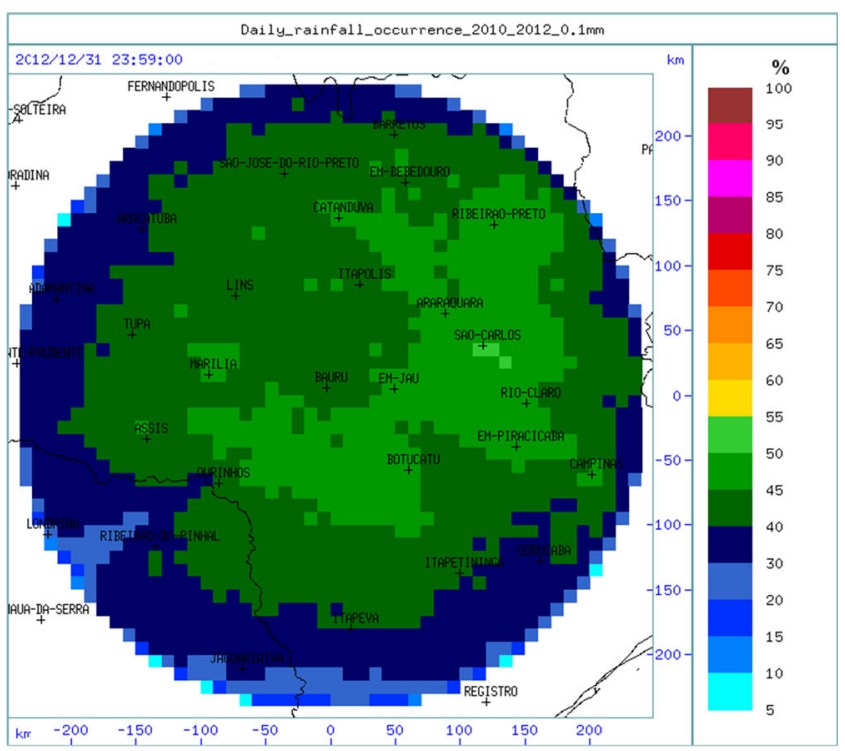

(b)

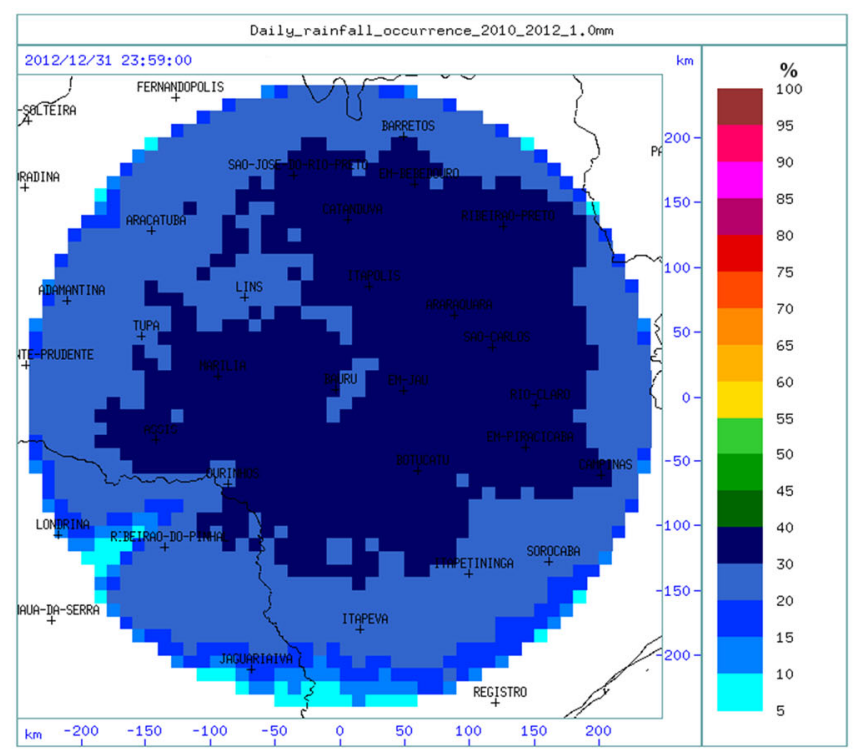

(c)

Fig. 3 Frequency of daily rainfall for the 3 years period, 2010-2012, for every pixel of $3.5 \mathrm{~km}$ CAPPI, when used threshold of a $0.0 \mathrm{~mm}$, b $0.1 \mathrm{~mm}$ and $\mathbf{c} 1.0 \mathrm{~mm}$

ZR relationships, respectively (Fig. 8); these are similar trends to previous results (Table 3 ).

Either of the two ZR expressions could have been used at this stage to derive the radar rainfall accumulation, but the convective $\mathrm{ZR}$ relationship was preferred as it better approximated the empirical cumulative distribution of the gauge precipitation (Fig. 9), and more closely resembled the type of precipitation expected in the state of Sao Paulo.

Once the error characteristics of the radar, in underestimating the observed rainfall using the convective $\mathrm{ZR}$ relationship, were identified, a correction of the systematic error could be derived. A linear regression was applied to the radar data set, using the rain gauge data set as the explanatory variable, as in the Eq. (2.1).

$\mathrm{RRc}=6.62+0.90 \times \mathrm{RR}$

where RRc is the daily corrected radar rainfall accumulation, estimated with Rosenfeld's ZR relationship. The reader should note that the correction of Eq. 2.1 is only applied to pixels identified as raining in the radar.

A comparison of the monthly totals of RRc and RR with the GP observations observed at the three stations shows 


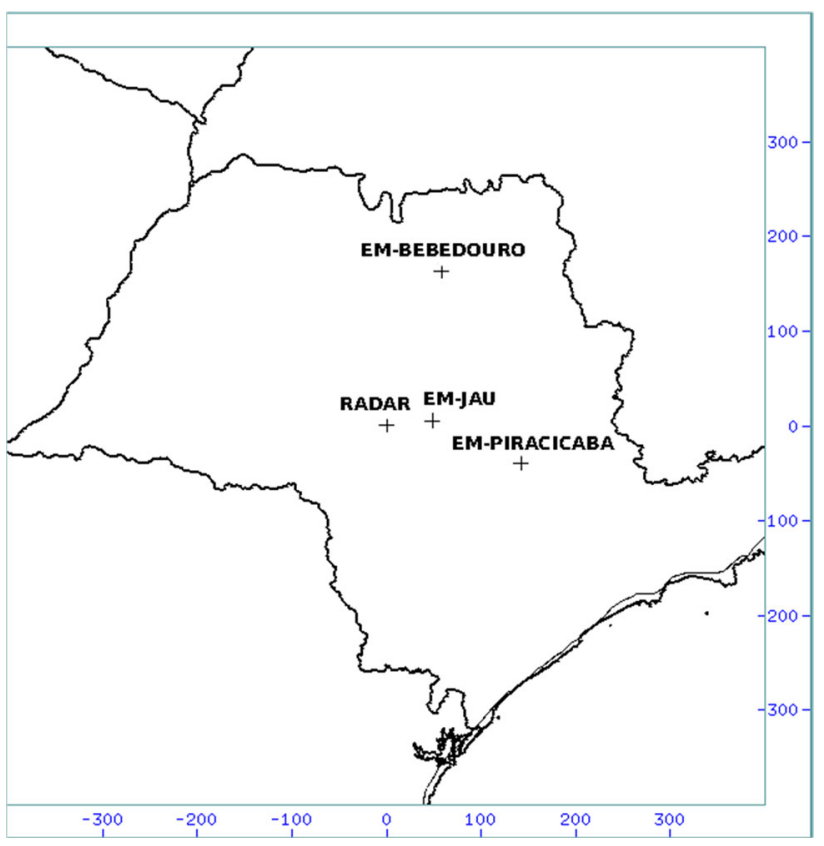

Fig. 4 Location of the three stations used for the calibration of the radar derived rainfall precipitation. Distances from the radar are indicated in the margins of the map that the performance of the radar rainfall correction data was generally impressive (Figs. 3, 10). However, there were cases where it did not perform well, for example in March 2011 for Bebedouro, and in January 2011 for Jau. In these cases, which were during the summer season for the Southern Hemisphere, the station gauges reported large amounts of daily rainfall, due to deep convection in the region and the radar did not quantify the precipitation during these events well. This is possibly due to distance and the blockage of the beam by mountains, in respect of Bebedouro and Jau, respectively. Nevertheless, the correction also performed well when applied to a test data set, that is, data from 2009, which were not used in the calibration procedure, from the Bebedouro and Piracicaba rain gauges, as shown in the plots of Fig. 11.

The above procedure resembles previous approaches for the quality control of radar data, mainly used to obtain reliable quantitative precipitation estimates (QPE) using weather radar. For instance, Chumchean et al. (2006) applied an integrate approach, which comprised the correction of reflectivity measurements, a combination of convective and stratiform ZR conversions and rain gauge
Fig. 5 Time series for the observed (GP) and derived radar (RR) daily rainfall at station Bebedouro, for the period 2010-2012. From top to bottom, the time series plots correspond, respectively, to the derived $R R$ using Marshall et al. (1955) ZR relationship, to the derived $\mathrm{RR}$ using Rosenfeld et al. (1993) ZR relationship and the rain gauge precipitation

\section{Daily RR and GP (mm) at Bebedouro, SP}

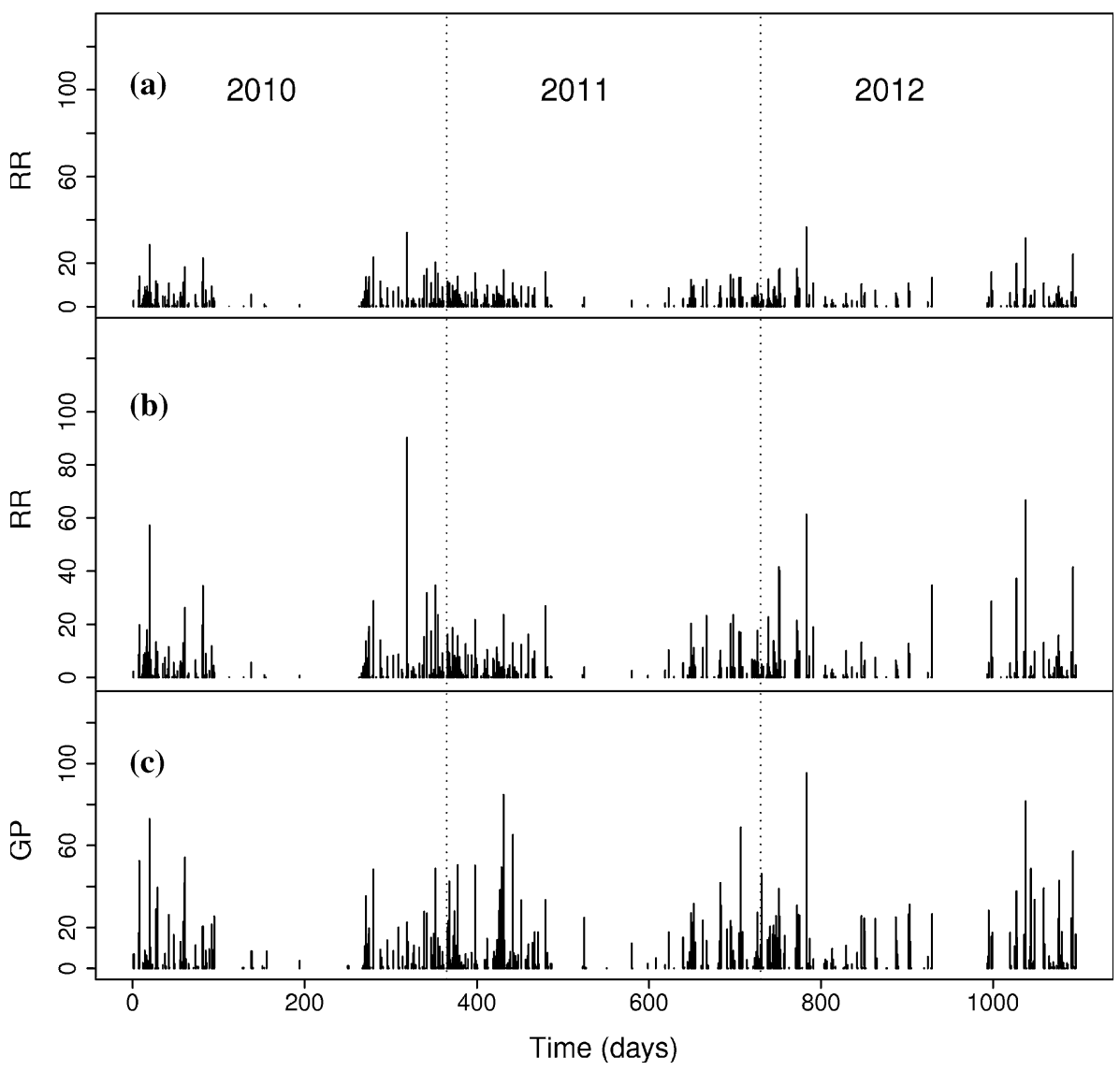


Fig. 6 Histograms for the difference RR-GP for the three rain gauges, located at Bebedouro, Piracicaba and Jau stations, respectively, from top to bottom of the figure. The histograms at the left correspond to the Marshall et al. (1955) ZR and those at the right side correspond to the Rosenfeld et al. (1993) ZR
Table 2 Summary of error statistics for the comparison between RR and GP, considering station individual data set and altogether
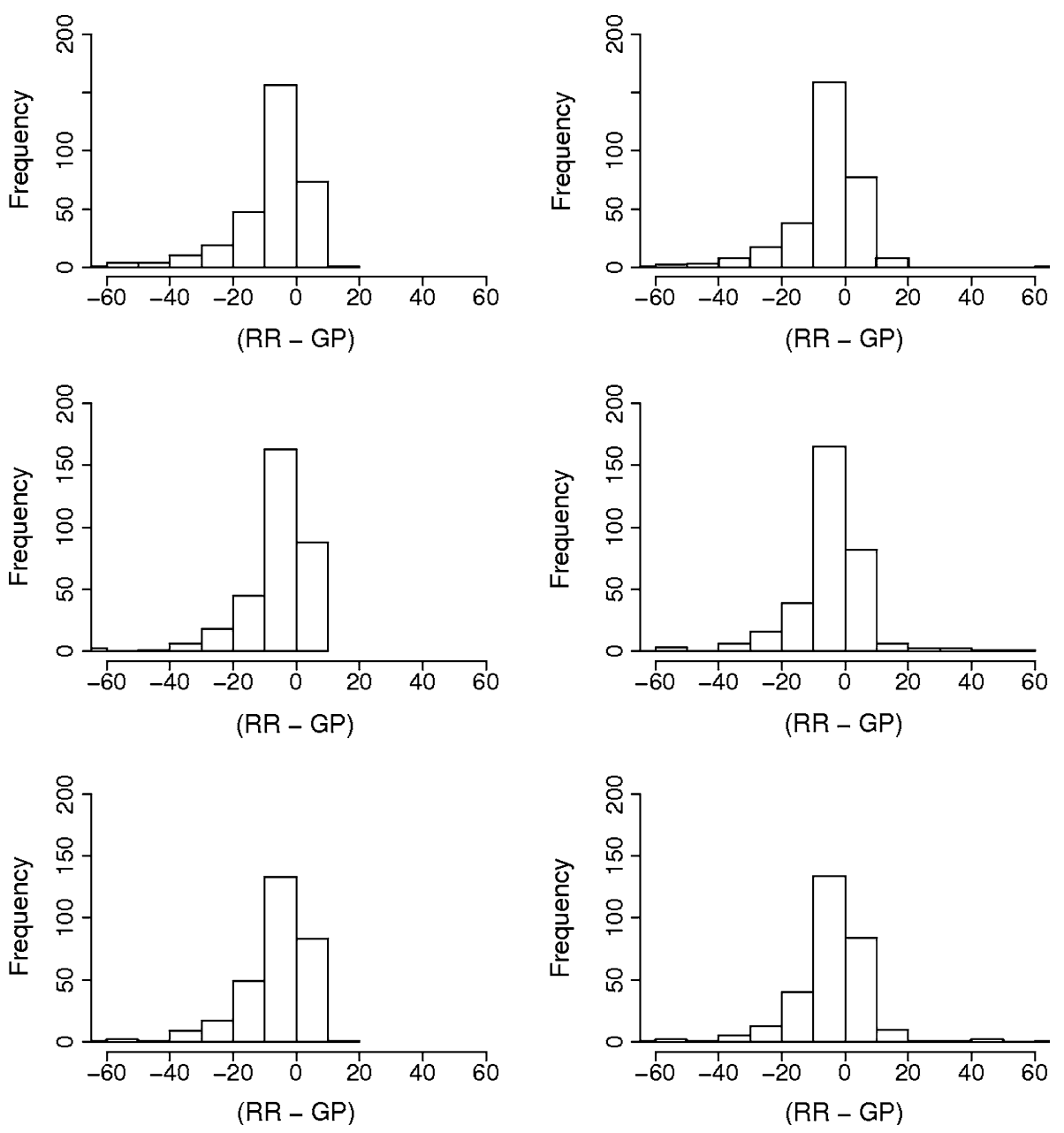

\begin{tabular}{lllllll}
\hline \multirow{2}{*}{ Station } & \multicolumn{2}{l}{ Marshall et al. (1955) } & & \multicolumn{2}{l}{ Rosenfeld et al. (1993) } & \\
\cline { 2 - 3 } & BIAS $(\mathrm{mm})$ & RMS (mm) & & BIAS (mm) & RMS (mm) & Distance (km) \\
\hline Bebedouro & -7.4 & 13.9 & & -5.5 & 12.9 & 170 \\
Piracicaba & -6.0 & 12.0 & & -4.4 & 12.7 & 150 \\
Jau & -7.2 & 14.4 & & -4.1 & 15.8 & 50 \\
All data & -6.8 & 13.4 & & -4.6 & 13.8 & - \\
\hline
\end{tabular}

adjustment through a Kalman filtering method. Their approach was very efficient at reducing error, more effectively than methods that consider just one source of error. Holleman (2007) described a mean-field bias adjustment algorithm, applied to $3 \mathrm{~h}$ radar rainfall accumulation data, and verified it using a long-term evaluation period; this substantially improved the QPE, by removing the meanfield bias. Both approaches are very useful for deriving a reliable field of ground precipitation by merging radar and rain gauge data. However, they differ from the methodology used above, as the aim here is to calibrate the radar data using point observations (which in the current application are from the three rain gauges), and then use the corrected radar estimates to verify NWP QPF. One advantage of this procedure lies in the possibility of using a few rain gauges, in case a more accurate blend analysis cannot be obtained. Tests with six more stations in the calibration process were also conducted, but they did not produce improvements in the results presented here (data not shown).

Another procedure carried out to prepare the radar data from Bauru, as reference for the NWP verification, was the interpolation of CAPPI data. These data were originally in azimuthal coordinates, and then were transformed to a 
Fig. 7 Scatterplots of daily derived radar precipitation $(\mathrm{mm})$ against observed daily precipitation $(\mathrm{mm})$ for the three rain gauges, at Bebedouro, Piracicaba and Jau, from top to bottom of the figure, respectively, and considering ZR due to Marshall et al. (1955), to the left, and Rosenfeld et al. (1993), to the right. The dotted line represents the perfect fit. Note that only $\mathrm{RR}$ data that are greater than $1.0 \mathrm{~mm}$ and GP, in which $(\mathrm{RR}-\mathrm{GP})>(\overline{G P}+2 s d)$, were used; thus, not all pairs (RR, GP) were presented
Fig. 8 As Fig. 7 but considering the rain gauge data altogether 24hrs Accumulated Rainfall
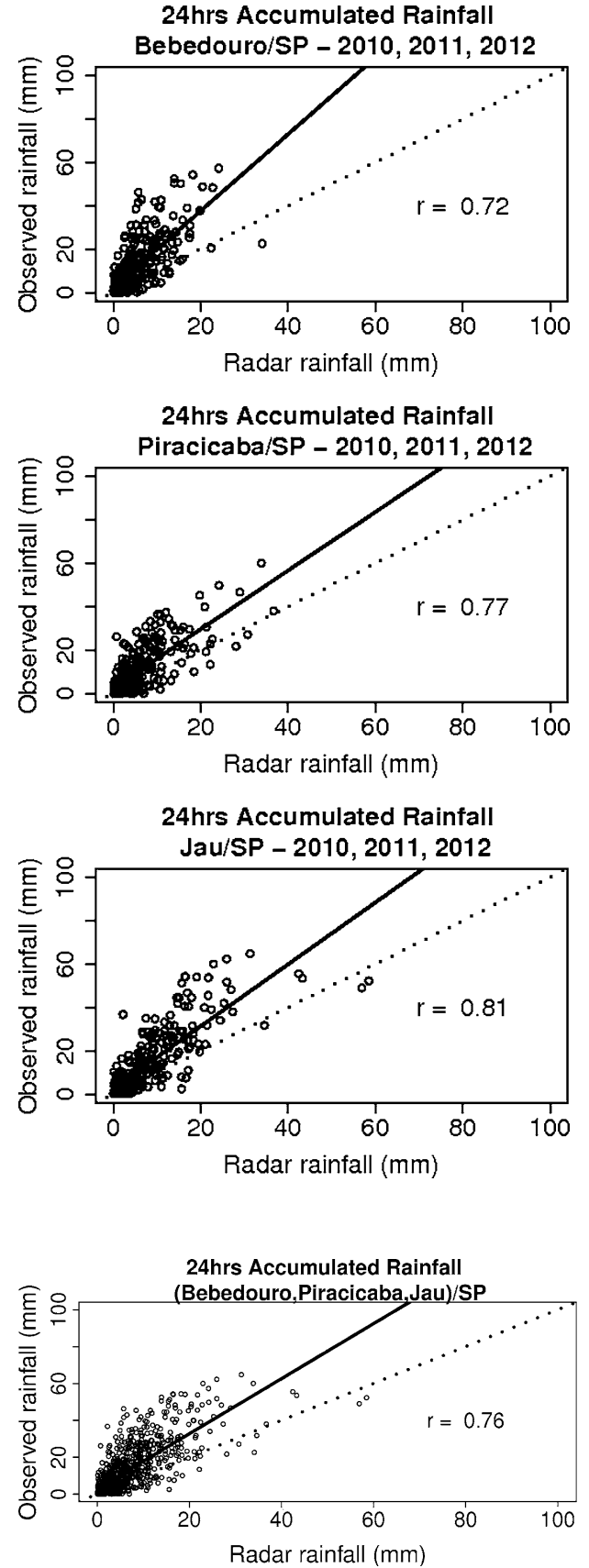

24hrs Accumulated Rainfall
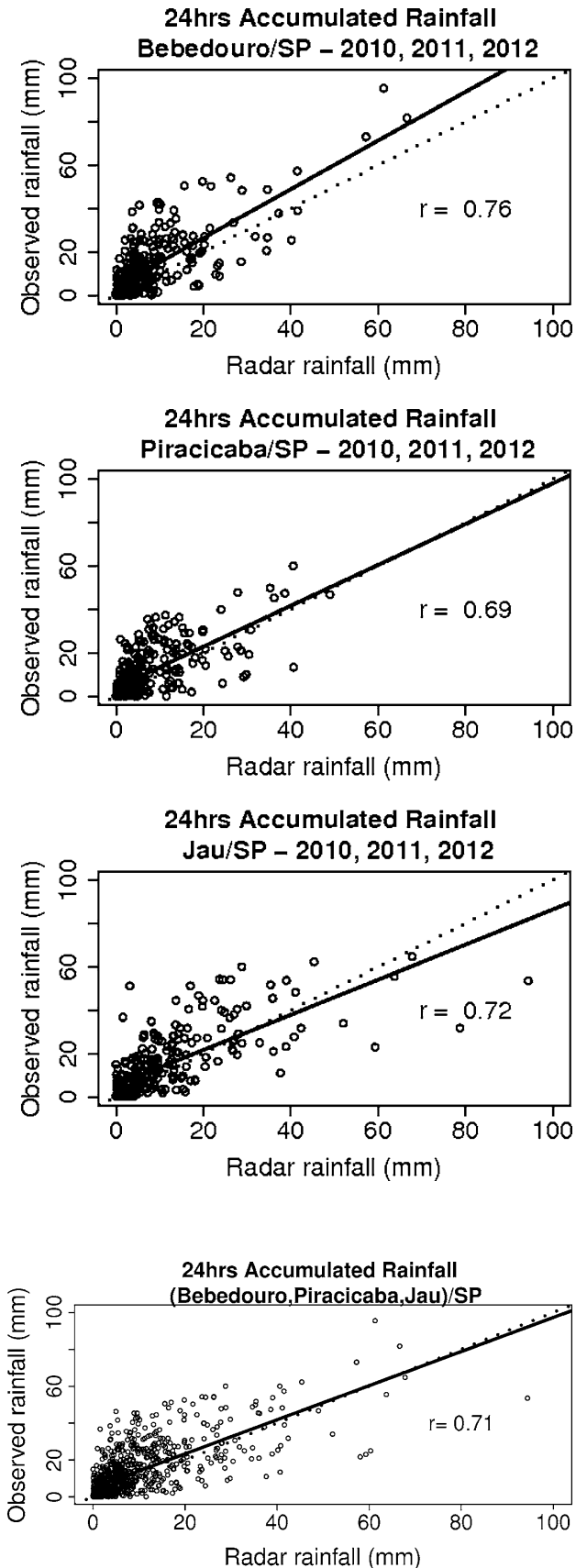

Table 3 Average of monthly rainfall and summary of the error statistics for the comparison of RR and RRc with GP, considering station individual data set, respectively without any correction (RR) and with correction (RRc) using the linear regression

\begin{tabular}{|c|c|c|c|c|c|}
\hline \multirow[b]{2}{*}{ Station } & \multirow[b]{2}{*}{ Average rainfall $(\mathrm{mm})$} & \multicolumn{2}{|c|}{ No correction } & \multicolumn{2}{|c|}{ With correction } \\
\hline & & BIAS (mm) & RMS (mm) & BIAS (mm) & $\mathrm{RMS}(\mathrm{mm})$ \\
\hline Bebedouro & 114.1 & -50.3 & 79.9 & -10.2 & 50.0 \\
\hline Piracicaba & 106.3 & -38.1 & 65.1 & 4.3 & 50.3 \\
\hline Jau & 122.8 & -34.3 & 65.0 & 2.3 & 45.4 \\
\hline
\end{tabular}




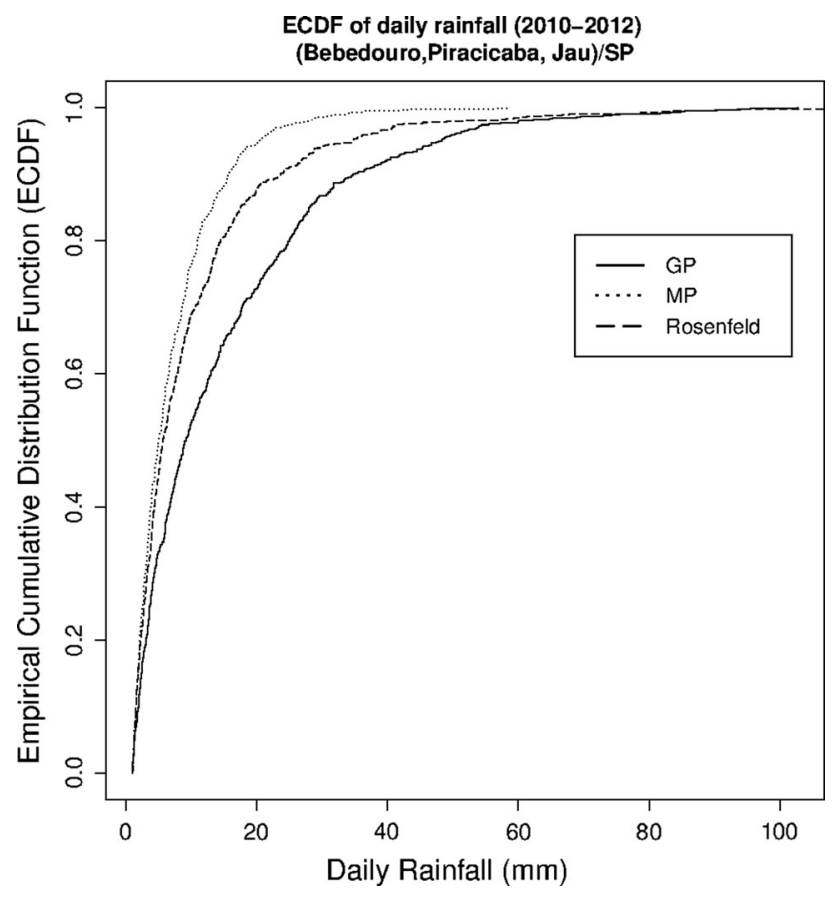

Fig. 9 Empirical cumulative daily rainfall distribution $(\mathrm{mm})$ for the rain gauges, Marshall-Palmer ZR and Rosenfeld ZR for the period 2010-2012

rectangular latitude/longitude grid, by spatial averaging. The procedure implies a loss of accuracy, as does the production of CAPPI data itself, but it was found adequate for examining the NWP QPF data. Nevertheless, the resulting CAPPI data set had the same grid spacing as the tested model $\left(10 \mathrm{~km}^{2}\right)$. The total domain was a $48 \times 48$ cell grids, resulting in a total area of $230,400 \mathrm{~km}^{2}$.

\section{Atmospheric model characteristics and verification methodology}

After the linear regression procedure was applied to the 3year data set, the corrected radar rainfall data were used to verify the accumulated rainfall derived from the NWP model. Any model can be used for this purpose, but the Eta was used, because it was the model used at IPMET and daily data that were suitable for the current research were available. The model is called Eta due to its use of the $\eta$ vertical coordinate, as described by Mesinger et al. (1988).

The configuration used was the same as that used by the Brazilian Institute for Space Research (INPE) of Brazil. The major features of the model applied for the current study follow the description of Chou et al. (2005): the Eta vertical coordinate; the forward-backward scheme to differentiate timing of gravity-wave terms; the Arakawa approach to differentiate spacing, with conservation of enstrophy and energy; the energy conservation in the transformations between the potential and kinetic energy, in differentiating spacing; the hydrostatic approximation; the convective precipitation was produced using KainFritsch scheme (Kain 2004); and the surface hydrology was solved with Chen scheme (Chen et al. 1997), which distinguishes twelve types of vegetation and seven types of soil texture. The prognostic variables were precipitation, temperature, surface pressure, turbulent kinetic energy and cloud liquid water ice. The model data used in the current study corresponded to three consecutive periods of $24 \mathrm{~h}$ rainfall accumulation after the model initialization, with horizontal grid spacing of $10 \mathrm{~km}$, extending from $24.5133^{\circ}$ to $20.1875^{\circ} \mathrm{S}$ and from $51.3951^{\circ}$ to $46.6599^{\circ} \mathrm{W}$, using the lateral boundaries of the Global Circulation Model of the Center for Weather Forecasting and Climate Research (CPTEC) of INPE, from 23 March 2010 (Fig. 12).

Three years of NWP prognoses (2010-2012) were used for the verification, corresponding to 791 cases of $24 \mathrm{~h}, 789$ cases of $48 \mathrm{~h}$, and 787 cases of $72 \mathrm{~h}$ rainfall forecasting. A verification methodology was applied, following Jolliffe and Stephenson (2011), based on the binary agreement of two classes that was considered for every mesh of the model grid, that is, if rain was predicted in the grid cell, or not. A contingency (Table 4) was used to analyse the categories associated with the occurrence, or not, of rainfall in the radar grid cell. Four situations were possible, and the number of times each of these occurred was counted:

- An observed event of rainfall according to the radar was forecast by the NWP ( $n_{1}=$ number of hits);

- An observed event of rainfall according to the radar was not forecast by the NWP ( $n_{2}=$ number of misses);

- Rainfall was forecast with the NWP and it did not occurred in the radar grid cell $\left(n_{3}=\right.$ number of false alarms);

- Rainfall was not observed according to the radar grid and it was not forecast by NWP $\left(n_{4}=\right.$ number of correct non-events).

The results computed for the contingency table were summarized with the probability of detection (POD) index, as in Eq. (3.1)

$\mathrm{POD}=\frac{n_{1}}{n_{1}+n_{2}} \times 100 \%$

and by the false alarm rate (FAR) index as in Eq. (3.2)

$\mathrm{FAR}=\frac{n_{3}}{n_{3}+n_{4}} \times 100 \%$

Another index related to the ratio of rainfall forecast to the actual observed rainfall was also calculated, called the frequency bias index (FBI), as described by Rossa et al. (2008): 

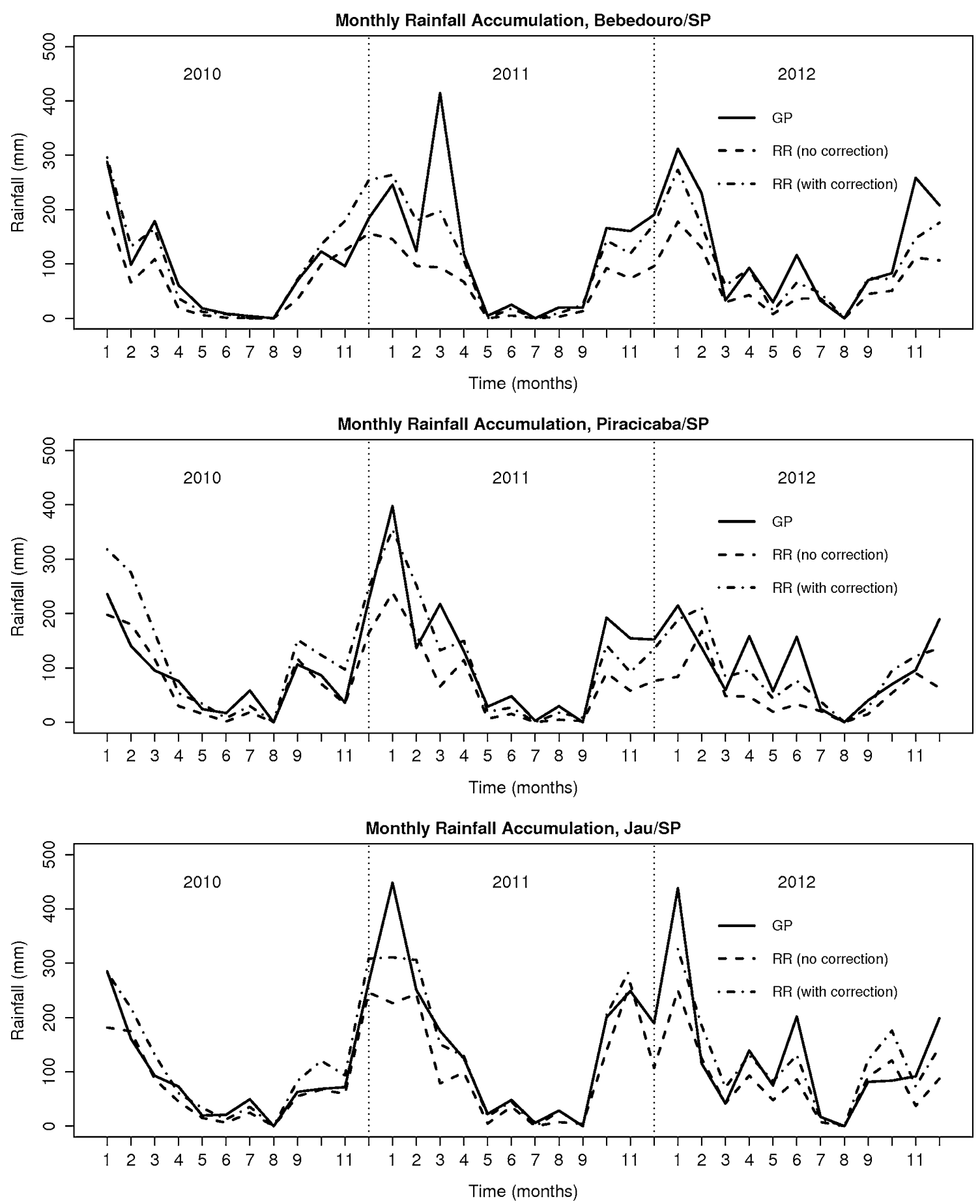

Fig. 10 Time series of the monthly rain gauge (GP) and radar (RR) rainfall accumulation, with (RRc) and without (RR) linear regression correction applied to the derived radar estimates, for the period from 2010 to 2012

$\mathrm{FBI}=\frac{n_{1}+n_{3}}{n_{1}+n_{2}}$

The FBI can range from zero to infinite, but unbiased $F B I$ value is 1.0 . Values less than 1.0 indicate that model predicts rain less frequently than is observed (under predicts), and values greater than 1.0 indicate that the model predicts rain more often than is observed (over predicts).

In addition to the categorical verification of the occurrence of rain in each grid cell, an evaluation of the quantitative rainfall forecasting was performed. The ability of the model to predict the daily rainfall accumulation within 

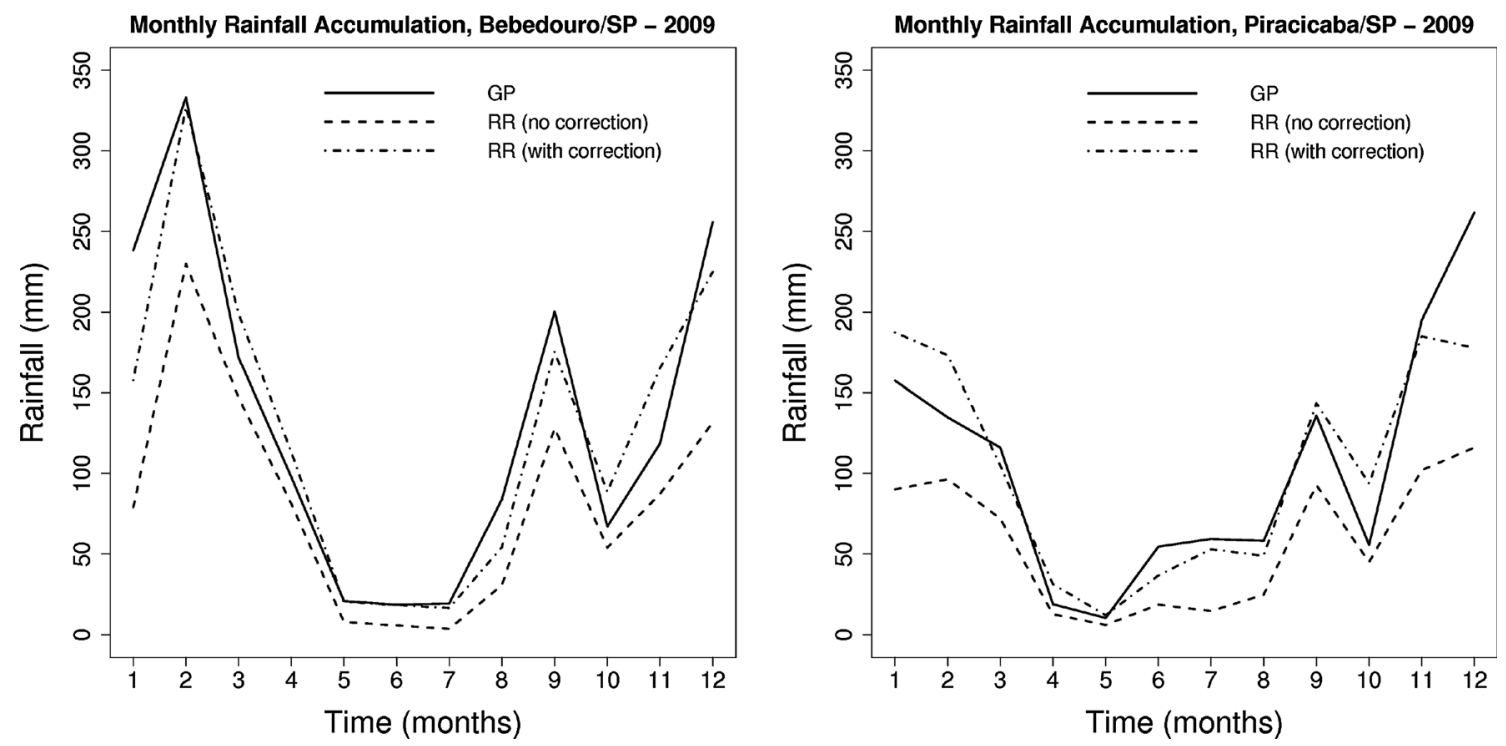

Fig. 11 As Fig. 10 for year 2009 (data set used as test only) and stations Bebedouro and Piracicaba

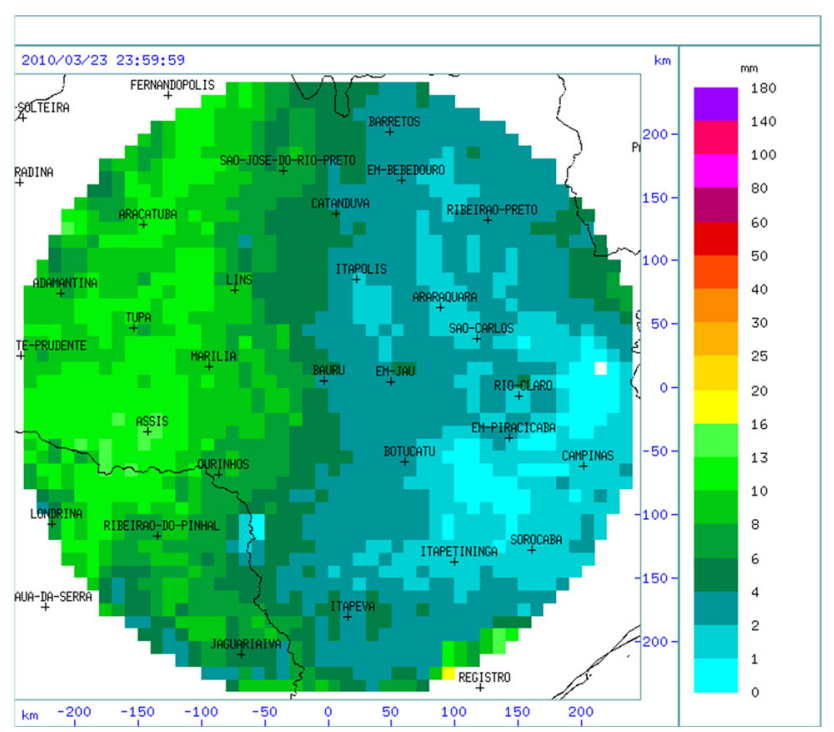

Fig. 12 Example of the forecast of rainfall accumulation over the period of $24 \mathrm{~h}$, derived with the Eta NWP model used in the current study, valid for 23 March 2010, at 00UTC

Table 4 Contingency table for the NWP verification

\begin{tabular}{llll}
\hline & & \multicolumn{2}{l}{ Radar observation } \\
\cline { 3 - 4 } & & Yes & No \\
\hline NWP Forecast & Yes & $\mathrm{n}_{1}$ & $\mathrm{n}_{3}$ \\
& No & $\mathrm{n}_{2}$ & $\mathrm{n}_{4}$ \\
\hline
\end{tabular}

each grid cell was examined if agreed with the radar at intervals of the distributions (Table 5): when there was no precipitation (no rain; A interval); the first quantile of $25 \%$ (weak precipitation; B interval); the quantile from 25
Table 5 Quantiles intervals of rainfall distribution for the model rainfall (MR) and corrected radar rainfall (RRc)

\begin{tabular}{|c|c|c|}
\hline Eta model & Radar & $\begin{array}{l}\text { Interval } \\
\text { letter }\end{array}$ \\
\hline $\mathrm{QMR}=0.0 \mathrm{~mm}$ & $\mathrm{QRRc}=0.0 \mathrm{~mm}$ & $\begin{array}{l}\text { A (no } \\
\text { rain) }\end{array}$ \\
\hline $\begin{array}{l}1.0 \mathrm{~mm}<\mathrm{MR}<\mathrm{QMR}_{25} \\
\quad \text { (weak) }\end{array}$ & $\begin{array}{l}7.52 \mathrm{~mm}<\mathrm{RRc}^{2}<\mathrm{QRRc}_{25} \\
\quad \text { (weak) }\end{array}$ & B \\
\hline $\begin{array}{l}\mathrm{QMR}_{25}<\mathrm{MR}<\mathrm{QMR}_{75} \\
\quad \text { (moderate) }\end{array}$ & $\begin{array}{l}\mathrm{QRRc}_{25}<\mathrm{RRc}<\mathrm{QRRc}_{75} \\
\quad \text { (moderate) }\end{array}$ & $\mathrm{C}$ \\
\hline MR > QRRc 75 (heavy) & $\mathrm{RRc}>\mathrm{QRRc}_{75}$ (heavy) & $\mathrm{D}$ \\
\hline
\end{tabular}

Table 6 Average of POD and FAR indexes, respectively, for three periods of rainfall NWP forecast when compared to the radar observation

\begin{tabular}{lccc}
\hline \multicolumn{4}{l}{ NWP forecast } \\
\hline Indexes & $24 \mathrm{~h}$ & $48 \mathrm{~h}$ & $72 \mathrm{~h}$ \\
\hline$\overline{P O D}(\%)$ & 90.7 & 87.3 & 85.4 \\
$\overline{F A R}(\%)$ & 44.7 & 47.0 & 49.2 \\
$\overline{F B I}$ & 1.74 & 1.75 & 1.78 \\
\hline
\end{tabular}

to $75 \%$ (moderate precipitation; $\mathrm{C}$ interval) and the quantile of $75 \%$ (heavy precipitation, D interval). Besides examining of the structure of the mean-field of precipitation, this analysis was useful for checking the performance of the model in predicting rainfall within these quantiles. Thus, the empirical cumulative distribution functions of MR and RRc were computed, to provide an overall comparison and for examining the quantile differences. An index was then computed, to express the proportion of the correct quantile prediction index (PCQI): 


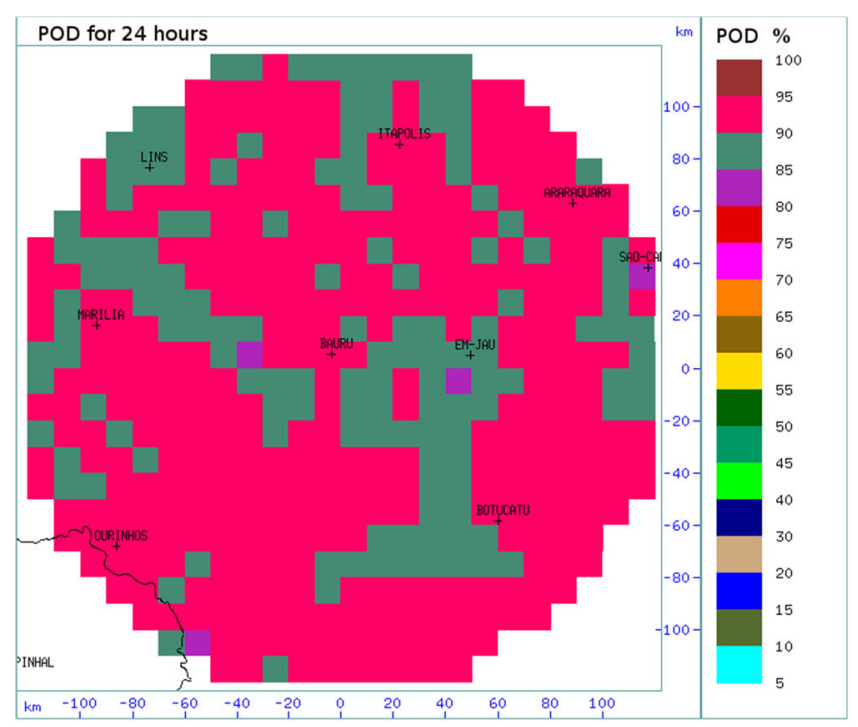

(a)

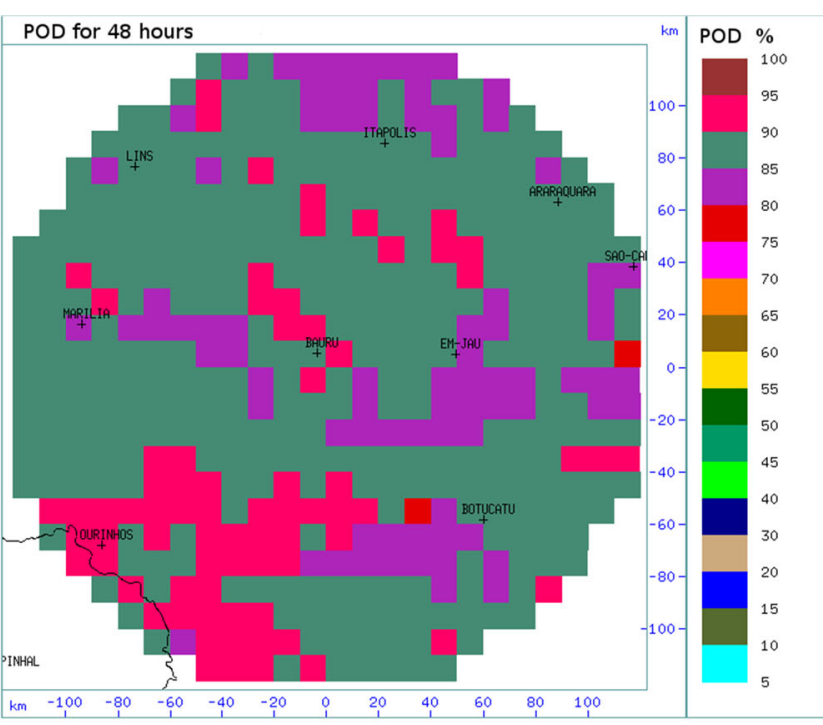

(b)

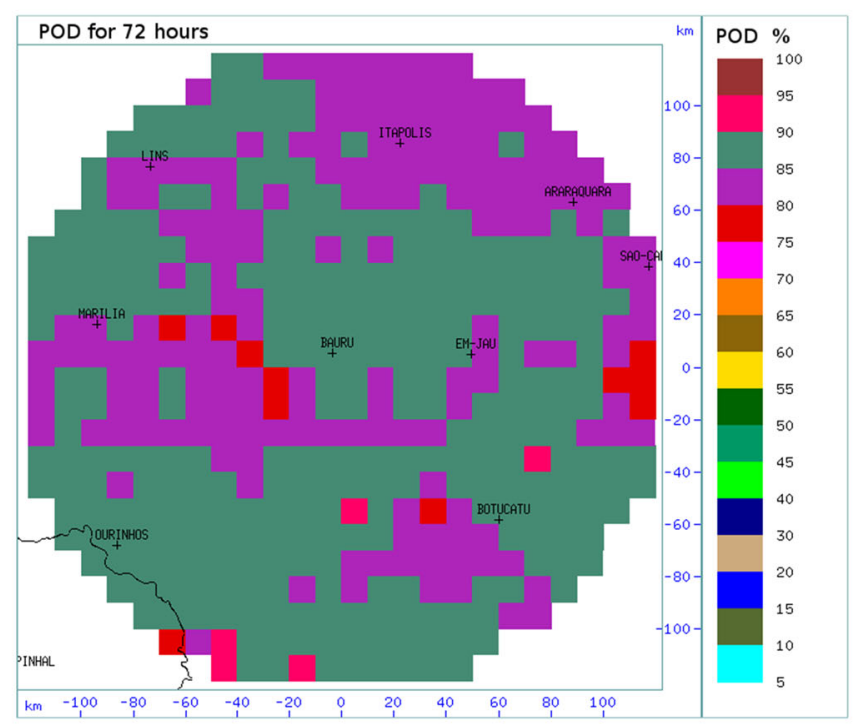

(c)

Fig. 13 POD in percentage for verification of NWP forecast in three times of rainfall accumulation, $\mathbf{a} 24 \mathrm{~h}, \mathbf{b} 48 \mathrm{~h}$ and $\mathbf{c} 72 \mathrm{~h}$, for the period of 3 years, from 2010 to 2012

$\mathrm{PCQI}=\left(\frac{1}{N} \sum_{i=1}^{N} q_{i j}\right) \times 100 \%$,

where $q_{i j}$ is 0 if the model does not predict rain within a given quantile interval and 1 if it does; $j$ represents the cell number and $i$ is the event number. $N$ is the total number of events for each of the forecast periods over 3-year time period (791, 789 and 787, for 24, 48 and $72 \mathrm{~h}$, respectively). The results are given as maps of PCQI for each of the interval quantiles and they can be interpreted as the ratio of correct predictions within each cell of the domain and within the specific range of values.

\section{Model verification results}

The verification indexes were computed by checking every output of the NWP model for the rainfall parameter. The analysis was restricted to the area within the $120 \mathrm{~km}$ range, because of the limitation of the radar in detecting precipitation beyond this range. The results for the three $24 \mathrm{~h}$ accumulation periods are summarized in Table 6 and they correspond to the average values over the entire radar grid between 2010 and 2012. The average values of POD indicate that there was a good agreement between the forecasted and observed rainfall values. Although, they 


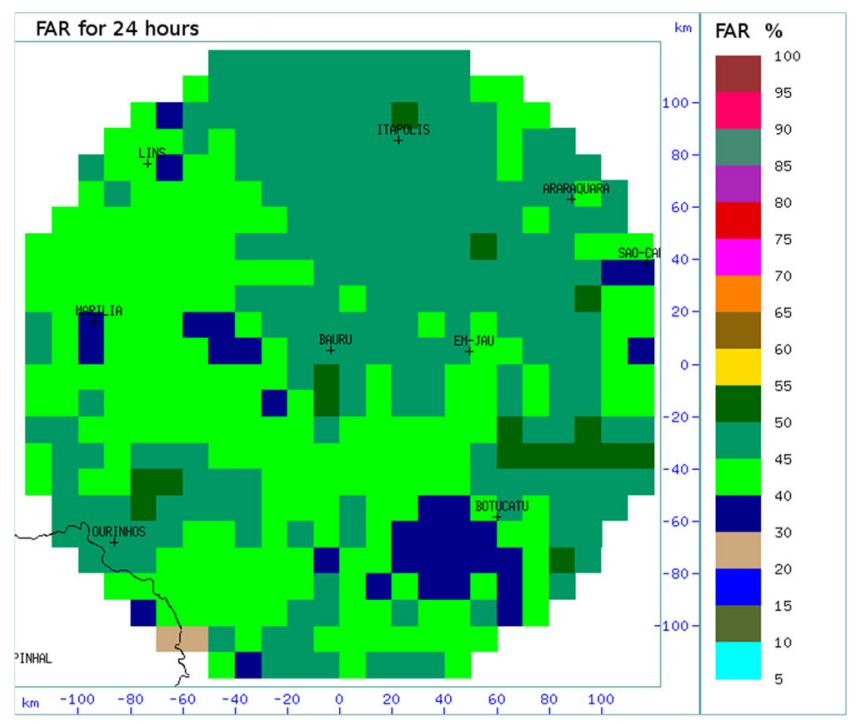

(a)

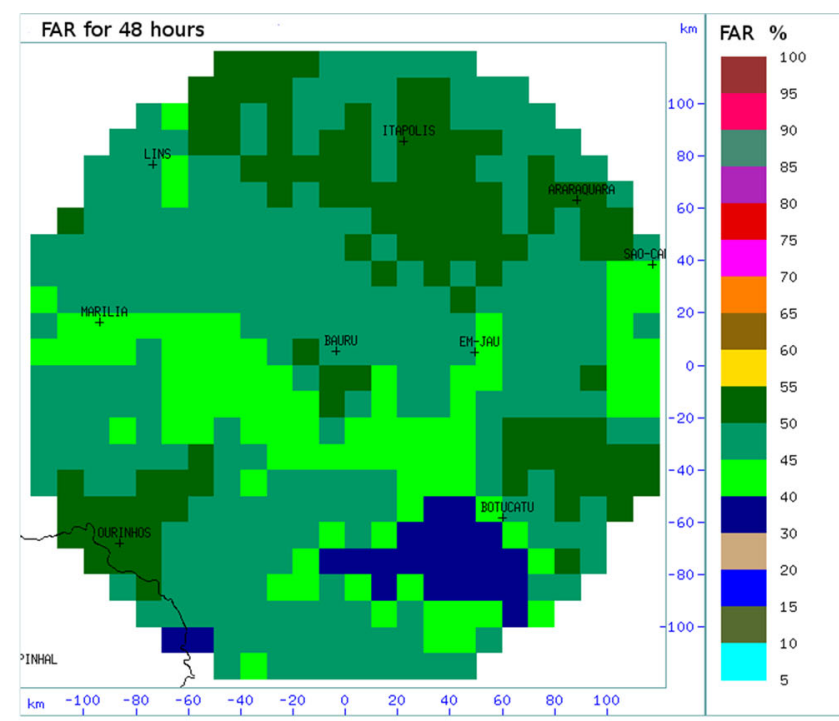

(b)

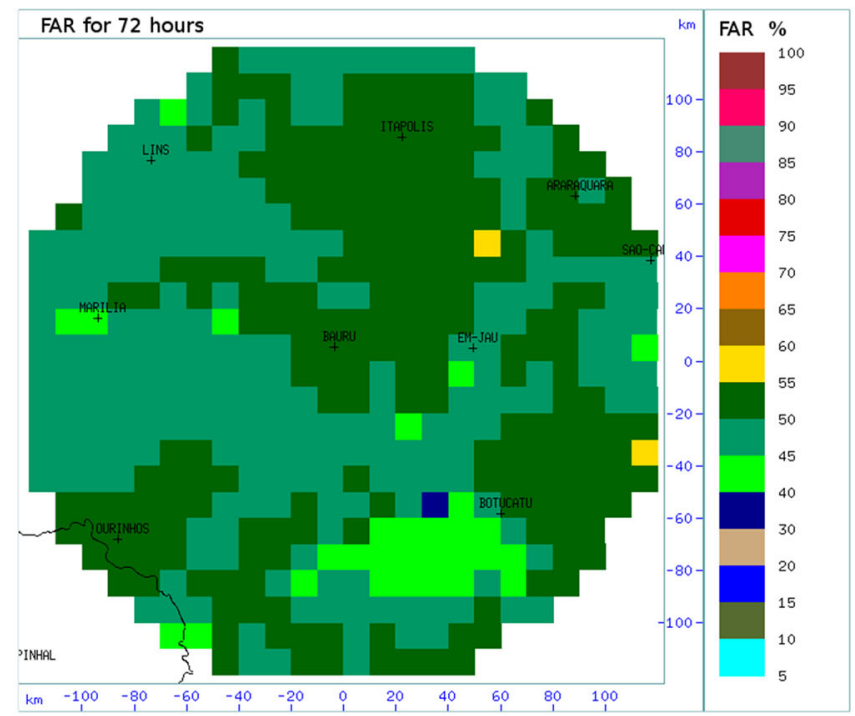

(c)

Fig. 14 False alarm rate index (FAR) in percentage for verification of NWP forecast at three times of rainfall accumulation, a $24 \mathrm{~h}, \mathbf{b} 48 \mathrm{~h}$ and c $72 \mathrm{~h}$, for the period of 3 years, from 2010 to 2012

also suggest slight differences among the forecast time periods and that the results were better for the time periods that were closer to the NWP initialization time. However, the average FAR was large for each of the three forecast periods, in that the NWP simulated rain in the radar grid in about half of the non-events; this is a poor result with respect to the ultimate uses of the NWP data. For example, if large areas of rainfall are falsely estimated, this will not be effective for applications such as crop irrigation planning.

Further assessment considers the spatial distribution of the 3-year POD average (2010-2012) at each grid point and shows differences among the forecast periods (Fig. 13). The values of the POD decreased with an increase in the forecast initialization time. This is particularly so in grid points that corresponded to either mountainous regions or those where there were horizontal changes in the terrain height (for example, see the $72 \mathrm{~h}$ forecasts in Fig. 13c and compare these to the Fig. 1).

The spatial distribution of the FAR shows that, for some points, lower FAR percentages were associated with higher POD percentages (Fig. 14); this can be interpreted as a good performance of the Eta model forecasting. Thus, as it can be observed in Fig. 14a, b, the darker areas correspond 


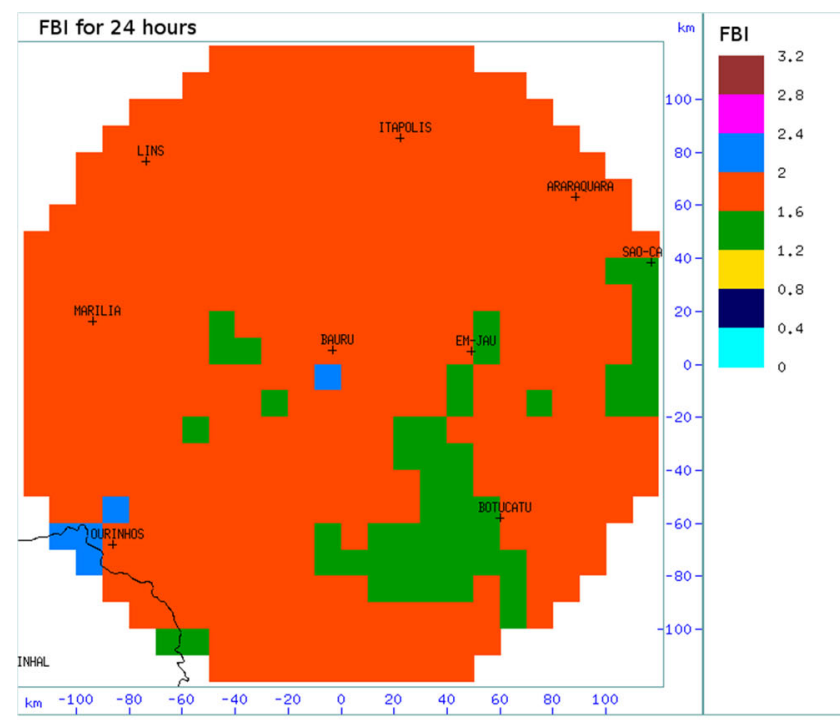

(a)

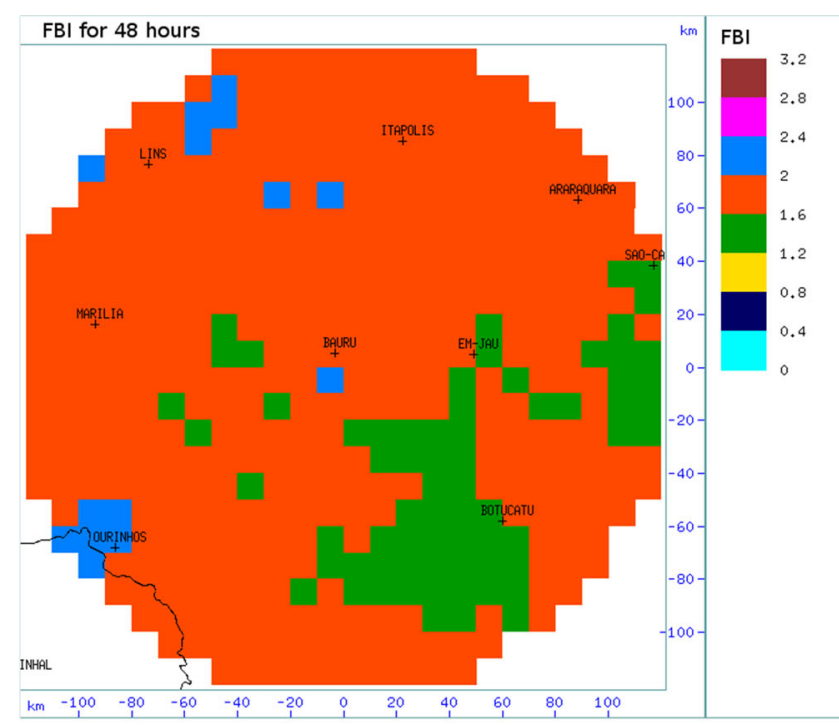

(b)

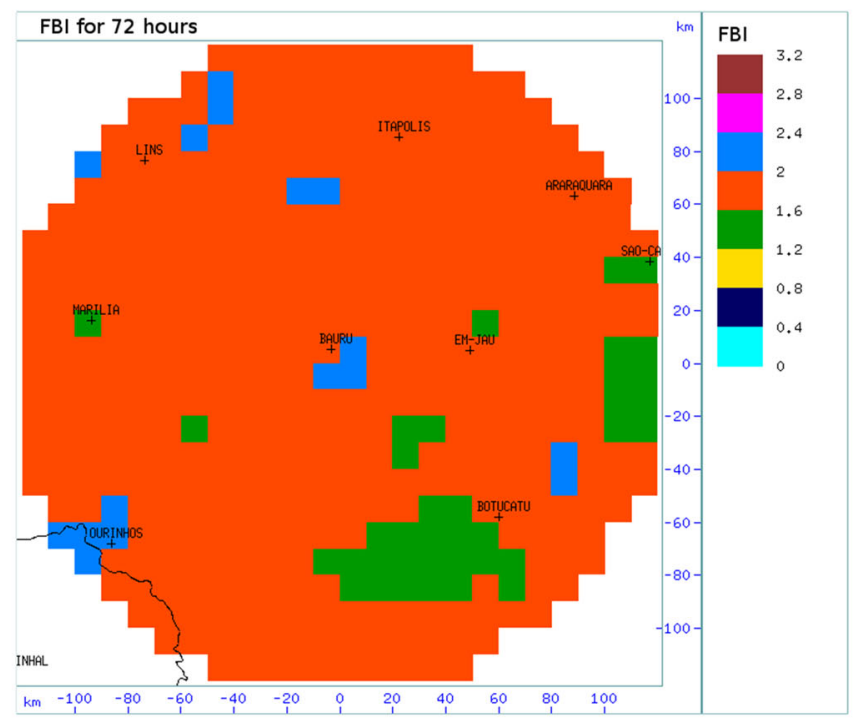

(c)

Fig. 15 Frequency bias index (FBI) for verification of NWP forecast at three times of rainfall accumulation, a $24 \mathrm{~h}, \mathbf{b} 48 \mathrm{~h}$ and $\mathbf{c} 72 \mathrm{~h}$, for the 3-year period (2010-2012)

to low FAR percentages and were computed for high elevation grid points, such in the Sierra de Botucatu, close to the radar.

The FBI results revealed that the model over predicted rain in most grid points (Table 6; Fig. 15). However, many values were between 1.6 and to 2.0 and there were places where the values were between 1.2 and 1.6. The latter correspond to mountainous places, such as the Sierra de Botucatu (Fig. 1).

In terms of the quantification of rainfall, for forecasts more than $24 \mathrm{~h}$ from the NWP initialization, the Eta underestimated the low portion of the rainfall distribution, i.e. $\mathrm{QMR}_{25}<\mathrm{QRRc}_{25}$ (Fig. 16a). The third model quantile
$\left(\mathrm{QMR}_{75}\right)$ was close to the third radar quantile $\left(\mathrm{QRRc}_{75}\right)$, despite the differences in Quantile-Quantile (Q-Q) plot (Fig. 16b). In addition, the PCQI (which expresses the overall percentage of the correct prediction in a given radar pixel) results revealed that the agreement, in the temporal distribution MR and RRc, was only about $50 \%$ (Fig. 17a). Nevertheless, a systematic feature of the Sao Paulo state rainfall can be drawn from these results, related to the orientation of synoptic and mesoscale precipitation systems that pass over the region (see Silva and Kousky 2012 as reference); it resembles the pattern formed by the 50-55\% verification range, observed in Fig. 17a. Since it is a strong feature in the data, it is worthwhile to mention that the 
ECDF of daily rainfall for MODEL and RADAR (2010-2012)

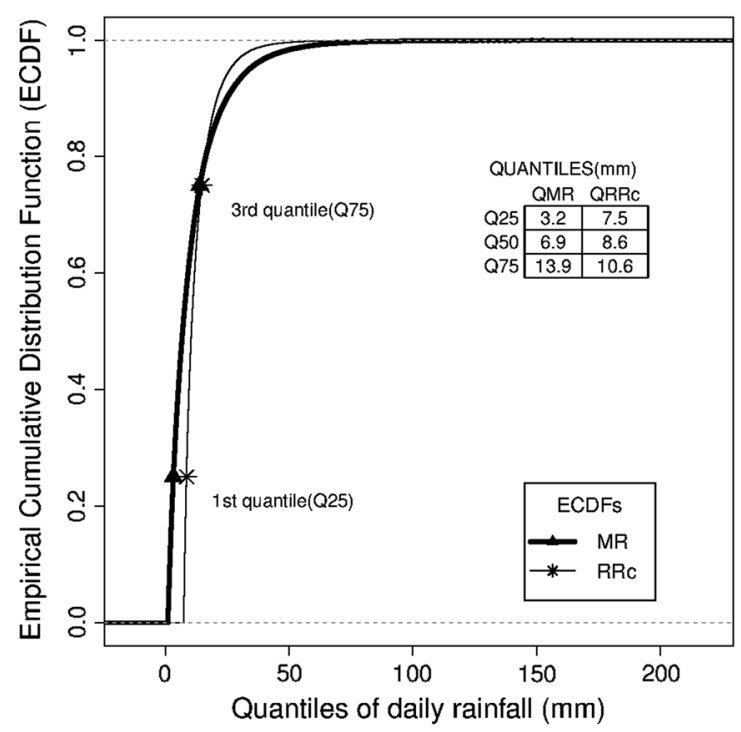

(a)
Q-Q plot for MR and RRc (2010-2012)

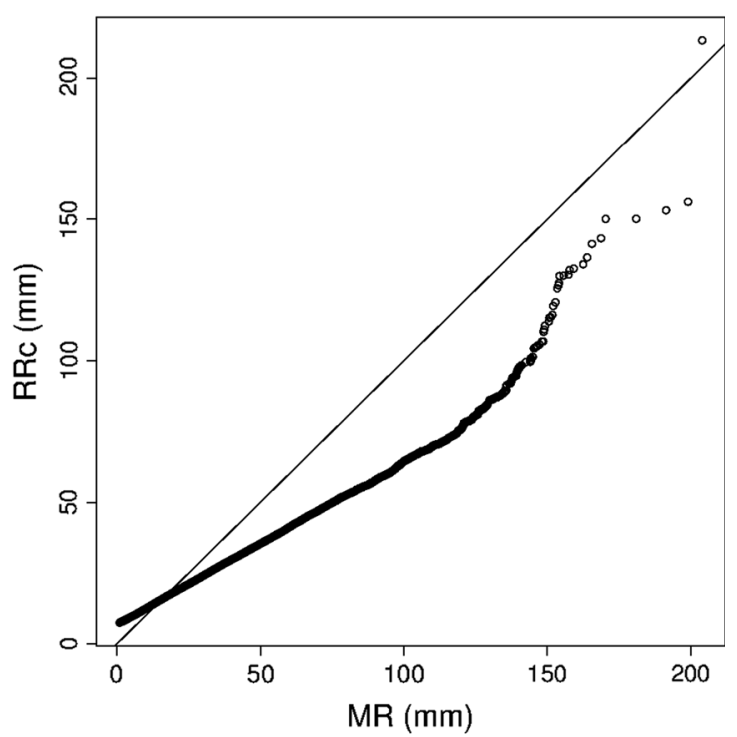

(b)

Fig. 16 Comparison between NWP model (MR) and corrected radar (RRc) empirical distributions of daily rainfall for the period 2010-2012: a Empirical cumulative distribution function for NWP model and corrected radar data, and b Quantile-Quantile plot

NWP model captured these atmospheric processes, as can be seen in the case of a cold front system that reached the state on 02 January 2011, as depicted in Fig. 18. However, in this event, the model produced more convection than it was observed in the radar and thus the rainfall was overestimated (Fig. 18c); though it is an expected result from the verification, the investigation of this aspect of the NWP model is beyond of the scope of the current study.

The results of PCQI for the B interval quantile (Fig. 17b) were weak for most of the grid points, since the NWP underestimated the observed precipitation for this interval (Table 5). The results obtained for the separate $\mathrm{C}$ and D intervals, as shown in Fig. 17c, d, tend to approximate to the result of the entire distribution, despite the observed errors at individual pixels. Furthermore, higher values of PCQI in Fig. 17d revealed an agreement of the distributions of MR and RRc (Fig. 16) in its upper portions, which is related to the forecasting of deep convective and orographic precipitation systems. However, the reader should be aware that this agreement is in the temporal distribution of MR and RRc, since the comparison of rain amount, as shown in the Q-Q plot (Fig. 16b), showed a less favourable pattern for higher quantiles.

\section{Conclusions and further work}

The main aim of the current study was to show that rainfall data derived from radar reflectivity could be an effective tool to verify NWP rainfall forecasts, despite inherent problems of the available weather radar data. Even the most powerful polarization and Doppler weather radar can still present problems when quantifying rainfall. Nevertheless, the approach in this study applied a linear correction to the radar data, based on ground rain gauges irregularly placed in the area of the radar. By correcting the radar data, unrealistic data were eliminated from the data set. A further cleanup procedure was performed to remove ground clutter from the data. Rosenfeld's ZR relationship was then used as reference series to examine the NWP forecasted data set. The choice of this ZR relationship, which is often used for convective precipitation, relies on the fact that it closely resembles the characteristics of the precipitation systems expected in the state of Sao Paulo. A better algorithm for the classification of precipitation types according to the ZR expression will allow more accuracy in the radar calibration for the future improvement of this work.

Indices were computed for binary verification of the rain forecasting in a given model grid cell. The results showed a good agreement between NWP rainfall forecasts and the radar derived rainfall, as indicated by the POD of each radar grid point. However, though the Eta model performs quite well in terms of hits, the false alarm rate average is close to $50 \%$.

The rainfall accumulation, in three $24 \mathrm{~h}$ periods after the model initialization time, was verified by comparing the rainfall distribution forecasted by the model and observed by the radar. The total distribution and interval quantiles were examined. The results for the level of agreement (maps of PCQI) indicated that the NWP forecasted rainfall 


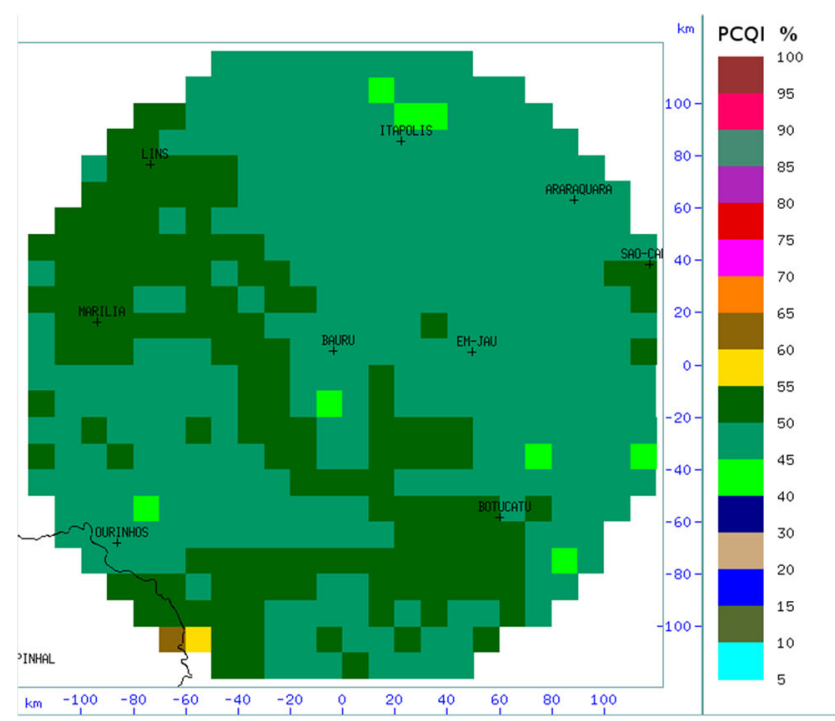

(a)

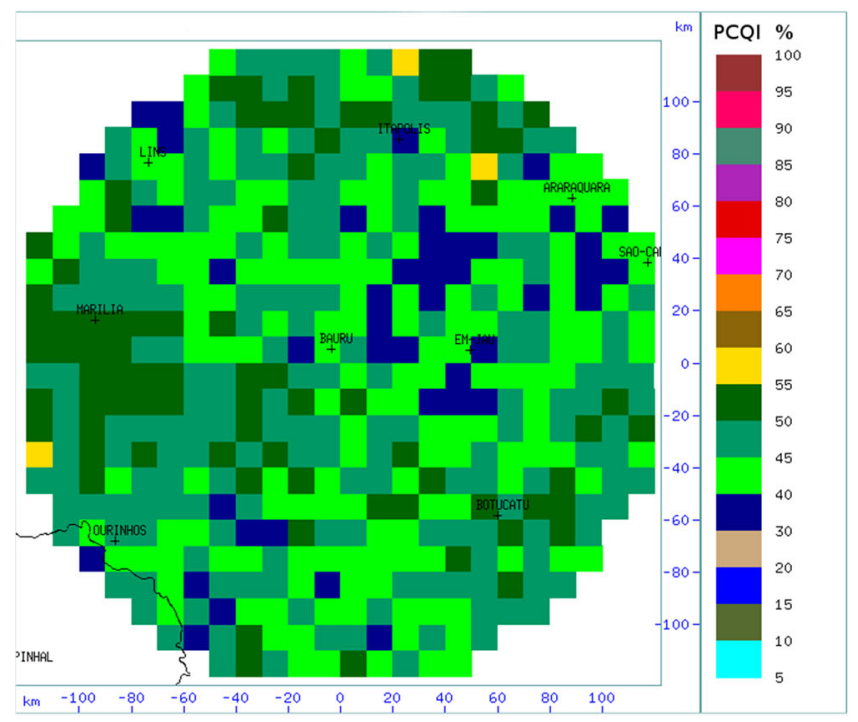

(c)

Fig. 17 PCQI in percentage, for total distribution and interval quantiles described in Table 5, expressing the NWP performance for predicting rainfall, after $24 \mathrm{~h}$ of model initial time, in the radar grid point as: a the overall result for the entire distribution, considering all quantile intervals; b considering only the B quantile interval, which

differed from the observational data for the low quantile interval, but was between 30 and $55 \%$ of the observational data for the moderate quantile and between 20 and $55 \%$ for the heavy quantile. This is a reasonable agreement, especially because the model captured features of the meteorological systems that pass through the Sao Paulo state, such as instability lines and cold fronts, as showed in the event of rainfall accumulation over $24 \mathrm{~h}$, from 01st to 02nd January 2011.

There is room for improvement of the current study. The correction of radar derived rainfall accumulation will be

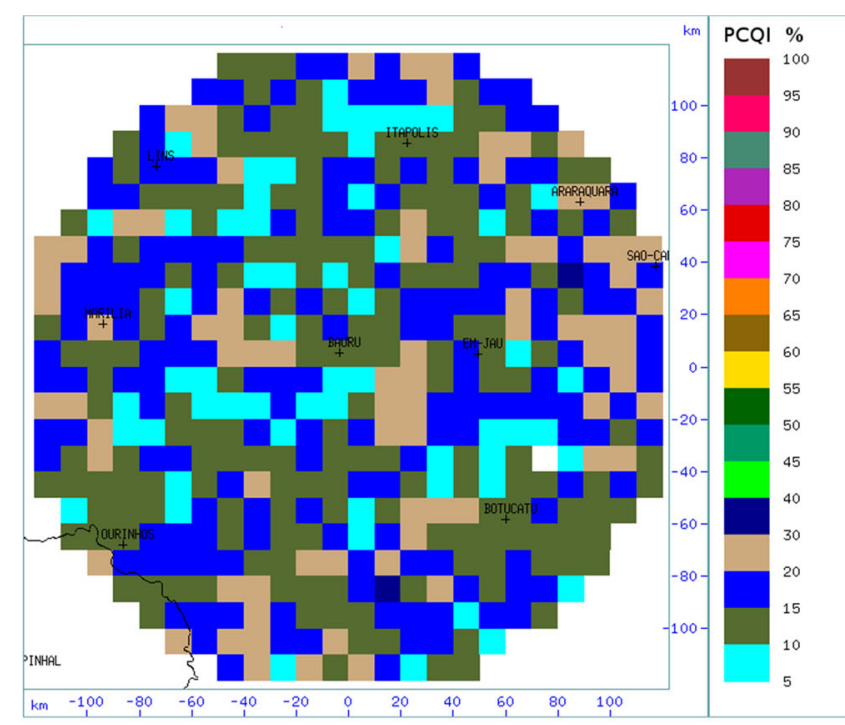

(b)

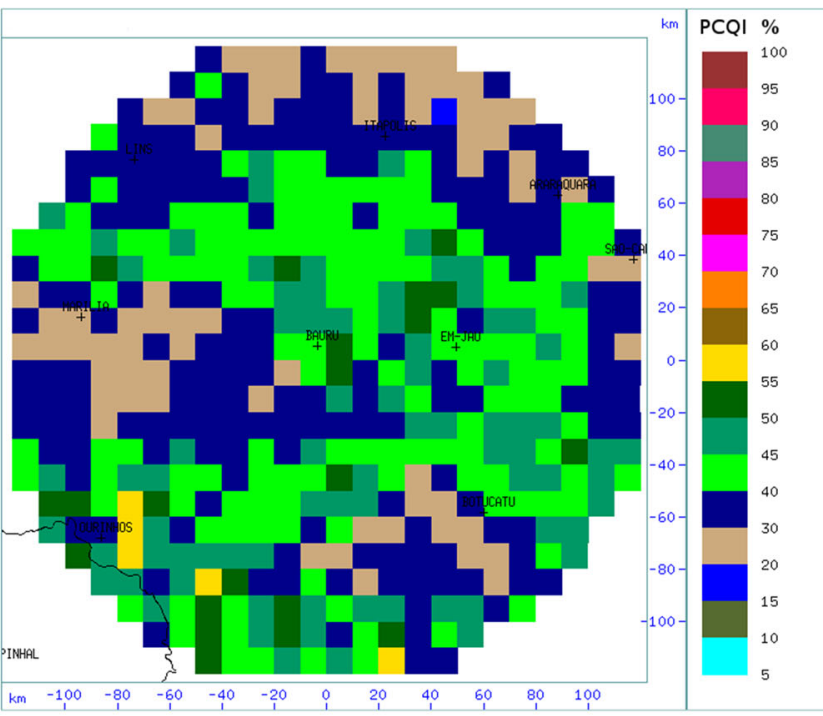

(d)

corresponds to weak precipitation; c considering only the $\mathrm{C}$ quantile interval, which corresponds to moderate precipitation and $\mathbf{d}$ considering only the $\mathrm{D}$ quantile interval, corresponding to heavy precipitation

improved using more rain gauges within the radar aerial coverage; these should focus on locations in which there are misclassifications of echoes, e.g. in mountainous areas, where the false alarm rate results are high.

The current study provides a useful methodology for the verification of NWP prognoses in places which lack ground-based validation sources, as the radar information can cover large areas with narrow horizontal grid spacing. It is also useful for those who only have access to radar CAPPI data and need to certify the quality of their NWP rainfall forecasts for multiple purposes. The results 


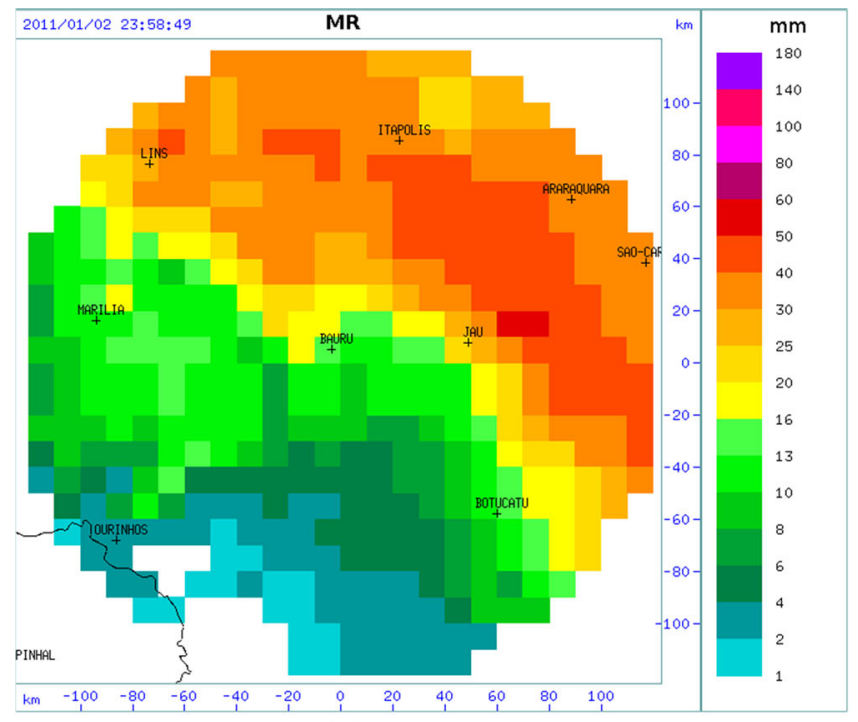

(a)

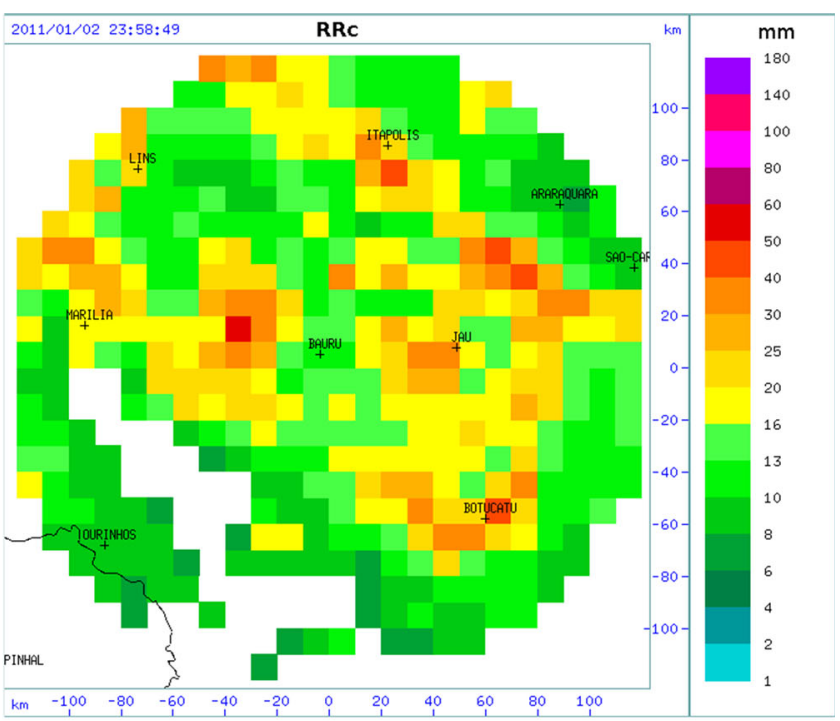

(b)

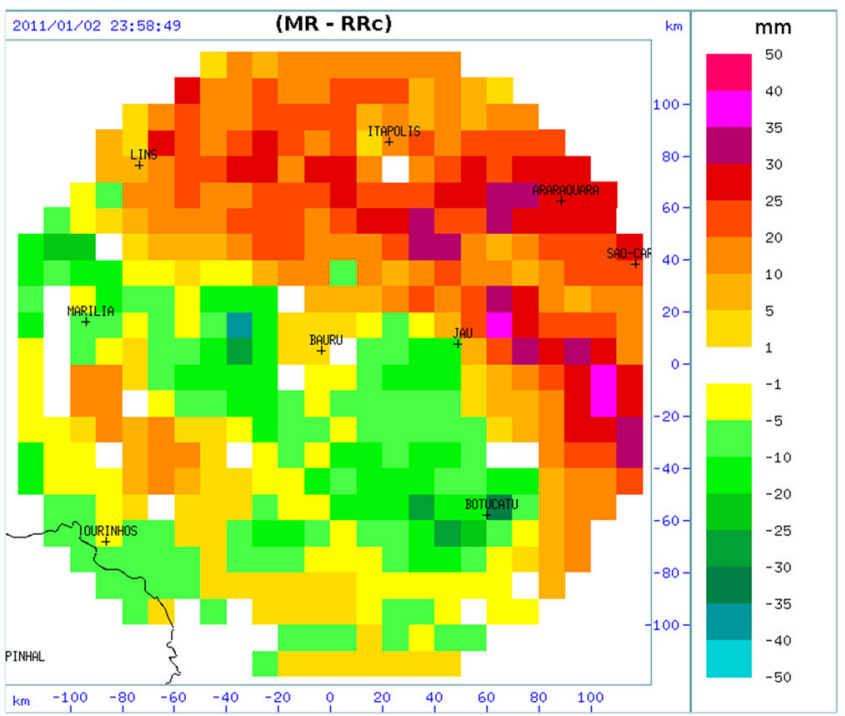

(c)

Fig. 18 Rainfall accumulation over 24 h for 02nd January 2011, respectively for: a Eta NWP model; b Corrected radar observation and $\mathbf{c}$ The differences between MR and RRc. The grids have the resolution of $10 \times 10 \mathrm{~km}$

presented in this study showed that the Eta model performed well, in terms of capturing the important features of rainfall, for the state of Sao Paulo, an area in the tropics, though it was not so effective for the quantification of rainfall. Thus, the work can be used for tuning of physical parameterization schemes of Eta model, such as convection and other associated processes, for improvement of its performance.

Acknowledgments The authors would like to thank the IPMET and UNESP for supporting this work and for the data of the Bauru radar. They are also grateful to the Citrus Experimental Station of the city of Bebedouro, to the Luiz de Queiroz College of Agriculture of the University of Sao Paulo (ESALQ/USP) and to the Faculty of
Technology of Jahú (FATEC/Jahú), for making their station rain gauge data available to IPMET and to this work. The graphic outputs of this study were produced with the $\mathrm{R}$ open source statistical programming language, developed by $R$ Development Core Team and it can be found at www.r-project.org. Finally, the authors thank the three anonymous reviewers for their important comments and suggestions for improvement of this manuscript.

\section{References}

Bean BR, Dutton E (1968) Radio meteorology. Dover, New York Berenguer M, Corral C, Sánchez-Diezma R, Sempere-Torres D (2005) Hydrological validation of a radar-based nowcasting technique. J Hydrometeorol 6:532-549 
Calvetti L, Pereira Filho A (2014) Ensemble hydrometeorological forecasts using WRF hourly QPF and topmodel for a middle watershed. Adv Meteorol 1:1-12

Chen F, Janjic Z, Mitchell K (1997) Impact of atmospheric surfacelayer parameterizations in the new land-surface scheme of the NCEP mesoscale Eta model. Bound Layer Meteorol 85:391-421

Chou SC, Bustamante JF, Gomes JL (2005) Evaluation of seasonal precipitation forecasts over South America using Eta model. Nonlinear Proc Geophys 12:537-555

Chumchean S, Sharma A, Seed A (2006) An integrated approach to error correction for real-time radar-rainfall estimation. J Atmos Ocean Technol 23:67-79

Doviak RJ, Zrnic DS (1984) Doppler radar and weather observations. Academic Press, Michigan University, London

Dufek AS, Ambrizzi T (2008) Precipitation variability in Sao Paulo State, Brazil. Theor Appl Climatol 93:167-178

Ebert EE, Gallus WA Jr (2009) Toward better understanding of the contiguos rain area (CRA) method for spatial forecast verification. Weather Forecast 24:1401-1415. doi:10.1175/2009WAF 2222252.1

Gabella M, Calvia V, Perona G (2004) Some examples on the use of radar observations for verification of NWP models in the alpine region. In: Proceedings, of the European conference on radar in meteorology and hidrology (ERAD), Kaltenburg-Lindau. Copernicus, Germany, pp 509-515

Holleman I (2007) Bias adjustment and long-term verification of radar-based precipitation estimates. Meteorol Appl 15:198-203. doi:10.1002/met.22

Jolliffe IT, Stephenson DB (2011) Forecast verification: a practitioner's guide in atmospheric science. Wiley, London

Kain J (2004) The Kain-Fritsch convective parameterization: an update. J Appl Meteorol 43:170-181

Laws JO, Parsons DA (1943) The relation of raindrop-size to intensity. Trans Am Geophys Union 24:452-460

Liebmann B, Jones C, De Carvalho L (2001) Interannual variability of daily extreme precipitation events in the state of Sao Paulo, Brazil. J Clim 14:208-218
Marshall JS, Palmer WM (1948) The distribution of raindrops with size. J Meteorol 5:165-166

Marshall JS, Langille RC, Palmer WM (1947) Measurement of rainfall by radar. J Meteorol 4:186-192

Marshall JS, Hitschfeld W, Gunn K (1955) Advances in radar weather. Adv Geophys 2:1-56

Mesinger F, Janjic Z, Nickovic S, Gavrilov D, Deaven D (1988) The step-mountain coordinate: model description and performance for cases of Alpine lee cyclogenesis and for a case of an Appalachian redevelopment. Mon Wea Rev 116:1493-1518

Peel MC, Finlayson BL, McMahon TA (2007) Updated world map of the Köppen-Geiger climate classification. Hydrol Earth Syst Sci 11:1633-1644

Probert-Jones JR (1962) The radar equation in meteorology. Q J Roy Meteorol Soc 88:485-495. doi:10.1002/qj.49708837810

Rosenfeld D, Wolff DB, Atlas D (1993) General probability-matched relations between radar reflectivity and rain rate. J Appl Meteorol 32:50-72

Rossa A, Nurmi P, Ebert E (2008) Overview of methods for the verification of quantitative precipitation forecasts. In Michaelides S (ed) Precipitation: advances in measurement, estimation and prediction. Springer, Berlin. ISBN: 978-3-540-77654-3

Silva VB, Kousky VEP (2012) The South American monsoon system: climatology and variability. In Wang, Shin-Yu and Gillies, R (ed), Modern climatology. Intech. doi:10.5772/2014

Silveira RB, Holt AR (2001) An automatic identification of clutter and anomalous propagation in polarization-diversity weather radar data using neural networks. IEEE Trans Geosci Remote Sens 39:1777-1788. doi:10.1109/36.942556

Vaisala (2014) RVP-8-digital IF receiver/Doppler signal processor: user's manual. Vaisala. www.vaisala.com

WMO (1996) Climatological Normals (CLINO) for the period 1961-1990. World Meteorol Organ. http://www.inmet.gov.br/ portal/index.php?r=clima/normaisClimatologicas 